\title{
LUT
}

Lappeenranta

University of Technology

\section{Effect of different co-solvents on biodiesel production from various low-cost feedstocks using Sr-Al double oxides}

Ambat Indu, Srivastava Varsha, Iftekhar Sidra, Haapaniemi Esa, Sillanpää Mika

This is a Final draft version of a publication

published by Elsevier

in Renewable Energy

DOI: $10.1016 / j . r e n e n e .2019 .08 .061$

Copyright of the original publication: () 2019 Elsevier Ltd.

Please cite the publication as follows:

Ambat Indu, Srivastava Varsha, Iftekhar Sidra, Haapaniemi Esa, Sillanpää Mika. (2019). Effect of different co-solvents on biodiesel production from various low-cost feedstocks using $\mathrm{Sr}-\mathrm{Al}$ double oxides. Renewable Energy, Vol. 146, p. 2158-2169. DOI: 10.1016/j.renene.2019.08.061 


\section{Effect of different co-solvents on biodiesel production from various low-cost}

\section{2 feedstocks using $\mathrm{Sr}-\mathrm{Al}$ double oxides}

3

4 Indu Ambat $^{\mathrm{a} *}$, Varsha Srivastava ${ }^{\mathrm{a}}$, Sidra Iftekhar $^{\mathrm{a}}$, Esa Haapaniemi ${ }^{\mathrm{b}}$, Mika Sillanpää $^{\mathrm{a}}$

5 a Department of Green Chemistry, School of Engineering Science, Lappeenranta

6 University of Technology, Sammonkatu 12, FI-50130 Mikkeli, Finland

7 b Department of Organic Chemistry, University of Jyväskylä, Finland

$8 *$ Corresponding Author (E-mail: indu.ambat@lut.fi)

\section{Abstract}

12 The main objective of the present paper comprises the investigation of biodiesel 13 production from low-cost feedstock such as lard oil and waste cooking oil (WCO) using 14 Sr-Al double oxides. Nanocatalyst was characterised FTIR, XRD, SEM, TEM, BET and 15 XPS. The Sr:Al with 3:1 molar ratio showed the best catalytic activity in the conversion 16 of both oils to fatty acid methyl ester. The effect of acetone and tetrahydrofuran (THF) as 17 a co-solvent for transesterification were compared and the best result was obtained with $185 \%$ THF. The mutual effect of the nanocatalyst and co-solvent on biodiesel production 19 was investigated. The characterisation of biodiesel synthesised from lard oil and WCO 20 was performed with GC-MS, ${ }^{1} \mathrm{H}$ and ${ }^{13} \mathrm{C}$ NMR. Moreover, the optimum reaction 21 parameters for transesterification reaction was analysed and the yield was determined by $22 \quad{ }^{1} \mathrm{H}$ NMR. The maximum yield of $99.7 \%$ and $99.4 \%$ of lard oil methyl ester and WCO 23 biodiesel were observed with a $0.9 \mathrm{wt} \%$ catalyst amount, 1:5.5 oil to methanol ratio in a 24 reaction time of 45 minutes at $50^{\circ} \mathrm{C}$ and $60^{\circ} \mathrm{C}$, respectively. The properties of biodiesel 25 from lard oil and WCO were determined by the EN 14214 method. The regeneration, 26 characterization and reusability of regenerated catalyst was observed.

Keywords: Biodiesel, lard oil, transesterification, $\mathrm{Sr}-\mathrm{Al}$ double oxides, waste cooking 29 oil

\section{Introduction}


32 Currently, the perpetual concern is the depletion of conventional fuels due to the 33 massive utilisation of fossil fuels. Moreover, the excessive use of petroleum products 34 leads to global warming and environmental pollution. Due to these issues, there is a need 35 for an alternative fuel [1,2]. Biodiesel is a suitable alternative fuel due to its 36 biodegradability, non-toxicity, renewability, lower emission of sulfur and carbon dioxide 37 and eco-friendly nature [3-5].

Biodiesel comprises fatty acid methyl esters, commonly produced by the 40 transesterification of fats or oils using methanol in the presence of a catalyst $[3,6,7]$. The 41 bottleneck issues associated with the transesterification process are the selection of 42 suitable feedstock, catalyst and an efficient method for the biodiesel production [2],[843 10]. The selection of feedstock for biodiesel production plays an important role in the 44 determination of fuel cost. Hence, keeping this point in mind the raw materials used in the present work includes lard oil and waste cooking oil. Furthermore, the application of 46 nanocatalytic technology for biodiesel production helps to improve catalytic activity, 47 reusability and stability $[2,5,11]$. The problems involved in the transesterification reaction such as a lower rate of reaction, poor phase separation and soap formation can

49 be resolved with the help of the co-solvent method [8-10] [12].

The present work was targeted to synthesise $\mathrm{Sr}-\mathrm{Al}$ double oxides with four different molar ratios metal ions. The application of $\mathrm{Sr}-\mathrm{Al}$ double oxides for biodiesel synthesis is 53 rather scanty and not well explored. Moreover, heterogeneous catalyst offers better 54 stability and reusability with lower cost in comparison with homogenous or biocatalyst 55 [11]. Later, synthesised Sr-Al double oxides were screened for biodiesel production and 56 the catalyst showed the best catalytic activity when used for the further reaction. 57 Furthermore, as the co-solvent plays an important role in the enhancement of biodiesel 58 yield and, therefore, the role of a different co-solvent with Sr-Al nanocatalyst in biodiesel 59 synthesis was also studied in the present work. The combined effect of the nanocatalyst 60 and co-solvent in biodiesel production from different feedstock was investigated. 61 Furthermore, to the best of our knowledge, the transesterification of lard oil and waste 62 cooking oil (WCO) using Sr-Al nanocatalysts and co-solvent have not been investigated.

63 The selection of oil was due to its low cost and availability. 
65 The characterisation of synthesised nanocatalyst was done using Fourier transform 66 infrared spectroscopy (FTIR), Scanning electron microscopy (SEM), X-ray diffraction 67 (XRD), Transmission electron microscopy (TEM) and Brunauer-Emmett-Teller (BET) 68 and X-ray photoelectron spectroscopy (XPS). The biodiesel obtained after a 69 transesterification reaction was analysed by gas chromatography with mass spectrometry 70 (GC-MS), ${ }^{1} \mathrm{H}$ and ${ }^{13} \mathrm{C}$ nuclear magnetic resonance (NMR). The reaction parameters such 71 as co-solvent percentage, reaction temperature, molar ratio of oil and methanol, catalyst 72 amount and reaction time were analysed. The physic-chemical properties of obtained 73 biodiesel was determined using EN 14214 method.

\section{2. Experimental}

\subsection{Chemicals}

Lard oil $($ FFA\% $=0.423)$ and waste cooking oil $($ FFA\% $=0.634)$ were obtained from 80 Sigma-Aldrich and household oil waste, respectively. The aluminium nitrate 81 nonahydrate, citric acid monohydrate acs reagent, methanol, acetone, tetrahydrofuran 82 (THF) anhydrous and heptane were purchased from Sigma-Aldrich. The strontium nitrate 83 was obtained from VWR International. All the chemicals were of analytical grade.

\subsection{Synthesis and screening of the catalyst}

Four different samples of Sr-Al mixed oxides were synthesised using the sol-gel citrate method. The samples were prepared by mixing metal nitrate of $\mathrm{Sr} / \mathrm{Al}$ in different molar ratios of 1:1, 1:0.51, 1:0.33, and 1:0.25 respectively and stirred for $1 \mathrm{~h}$. Thereafter,

90 stoichiometric amount of citric acid was added to metal nitrate solution followed by 91 additional stirring for $1 \mathrm{~h}$ [45]. The molar ratios of citric acid to total metal cations 92 concentration were kept 2[46]. The mixture was then heated over $100^{\circ} \mathrm{C}$ until a clear 93 transparent gel was obtained. The resultant gel was dried at $110^{\circ} \mathrm{C}$ overnight and then 94 dried gel was grounded to get fine powder which was further calcined at $700^{\circ} \mathrm{C}$ for $5 \mathrm{~h}$. 
95 The catalysts were screened for fatty acid methyl ester (FAME) production from lard oil 96 and WCO.

97

\subsection{Characterisation of catalyst}

99

XRD patterns of synthesised catalyst were captured with PANalytical - Empyrean Xray diffractometer over a $2 \theta$ range of $10-120^{\circ}$ with an X-ray source Co-K $\alpha$ of $0.178 \mathrm{~nm}$ at $40 \mathrm{~mA}$ and $40 \mathrm{kV}$. FTIR (Vertex 70 model by Bruker) used to analyse functional groups of synthesised catalyst by capturing IR spectra from 400 to $4000 \mathrm{~cm}^{-1}$. SEM images of nanocatalysts were obtained by spreading the sample on colloidal graphite with $5 \mathrm{kV}$ accelerating voltage (SEM, Hitachi SU3500). TEM images of the samples were captured using HT7700 (Hitachi). For attaining TEM images, the nanocatalyst was dispersed in ethanol and sonicated for $25 \mathrm{~min}$ and a drop of suspension was added to the carbon coated copper grid. Surface area, pore diameter and pore volume of synthesised catalysts were determined using BET surface area analyser (BET, Micromeritics Tristar II plus). Prior to performing BET analysis, the catalyst samples were degassed at $35^{\circ} \mathrm{C}$ overnight to remove the moisture from the samples. The surface composition and the binding energies of elements in nanocatalysts were examined by ESCALAB 250 model XPS with an Al$\mathrm{K}$ X-ray source of $1486.6 \mathrm{eV}$.

\subsection{Reaction procedure}

Lard and waste cooking oil were used as feedstock for biodiesel production. The 118 fatty acid methyl ester production from each oil using different ratios of $\mathrm{Sr}-\mathrm{Al}$ double 119 oxides was done in a $250 \mathrm{ml}$ three neck round bottom flask with mechanical stirrer and 120 reflux condenser at $60^{\circ} \mathrm{C}$ by mixing methanol to oil in a 5:1 molar ratio and with $2.5 \mathrm{wt} \%$ 121 of each catalyst for $120 \mathrm{~min}$. The various methanol to oil ratios were reported for 122 transesterification studies and theoretically 3: 1 molar ratio is enough for 123 transesterification reaction [11, 35, 36, 37]. All the reactions were conducted in triplicates. 124 The phase separation of fatty acid methyl ester, glycerol and catalyst were achieved by 125 the centrifugation of the samples after each reaction. The selection of the best catalyst for 126 further studies was completed by analysing the obtained FAME concentration. In 
127 addition, excess methanol in ester phase and catalyst after the reaction were recovered 128 after the transesterification reaction. The separated catalyst was washed with methanol 129 and heptane to remove impurities. After washing, the catalyst reactivation was achieved 130 by drying the recovered catalyst at $60^{\circ} \mathrm{C}$ followed by calcination at $700^{\circ} \mathrm{C}$ for $5 \mathrm{~h}$.

131

132

As an extension of this work, the influence of a different co-solvent like acetone and 134 THF on biodiesel production was investigated. The transesterification reactions were 135 conducted for the comparison of co-solvents by varying its amount from 5 to $20 \mathrm{wt} \%$ in each reaction with the best catalyst obtained after the screening procedure. The resulting optimised amount of the best co-solvent with the greatest performing nanocatalyst was used for further biodiesel production studies.

\subsection{Analytical methods}

The biodiesel attained after the transesterification reaction of lard and WCO was analysed by GC-MS (Agilent-GC6890N, MS 5975) with Agilent DB-wax FAME analysis GC column dimensions $30 \mathrm{~m}, 0.25 \mathrm{~mm}, 0.25 \mu \mathrm{m}$. The inlet temperature was $250^{\circ} \mathrm{C}$ and the oven temperature was programmed at $50^{\circ} \mathrm{C}$ for $1 \mathrm{~min}$ and it raises at the rate of $25^{\circ} \mathrm{C} / \mathrm{min}$ to $200^{\circ} \mathrm{C}$ and $3^{\circ} \mathrm{C} / \mathrm{min}$ to $230^{\circ} \mathrm{C}$ and then it was held for $23 \mathrm{~min}$.

148 Moreover, ${ }^{1} \mathrm{H}$ and ${ }^{13} \mathrm{C}$ NMR (Bruker) were used for the estimation of fatty acid esters content and conformation of esters in each sample, respectively. For NMR analysis, fatty acid methyl esters were examined by ${ }^{1} \mathrm{H}$ NMR and ${ }^{13} \mathrm{C}$ NMR at $400 \mathrm{MHz}$ with $\mathrm{CDCl}_{3}$ as a solvent. The percentage conversion of oil to fatty acid methyl esters $(\mathrm{C} \%)$ and biodiesel yield are determined by equation 1 and 2 , given below [11,37].

$$
C(\%)=\frac{2 \times \text { Intergration value of protons of methyl ester }}{3 \times \text { Intergraton value of methyl protons }} \times 100(\text { Eq. } 1)
$$

155

$$
\text { Biodiesel yield }(\%)=\frac{\text { mass of biodiesel }}{\text { mass of oil }} \times 100
$$


However, the biodiesel production was also affected by the reaction parameters

160 such as the amount of catalyst, oil to methanol ratio, reaction temperature and reaction 161 time.

162

163

164

165

166

167

168

169

170

171

172

173

174

175

176

177

178

179

180

181

\section{Result and discussion}

\subsection{Screening and selection of nanocatalyst for biodiesel production}

The catalytic performance of different molar ratio of Sr:Al catalyst was analysed for the biodiesel production from waste cooking oil and lard oil. The catalytic activity of each catalyst and the viscosity of different FAME samples was indicated in Table 1. The high catalytic activity of Sr:Al with 1.0.33 molar ratio is due to the optimum loading of aluminium ions and strontium ions to nanocatalyst, which offers a proper interaction between the components of the catalyst. Hence, the appropriate structure of the catalyst provides sufficient active sites for the fatty acids to bind with the nanocatalysts. Moreover, only the biodiesel obtained using Sr:Al with molar ratio 1:0.51 and 1:0.33 were within the EN ISO 3104 limits. Considering the following results, Sr:Al with molar ratio 1:0.33 catalyst was chosen for further optimisation studies. Thereafter, Sr:Al with molar ratio 1:0.33 denoted as Sr: 0.33Al.

Table 1. The efficiency of various catalyst for transesterification

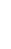

\begin{tabular}{lcccc} 
No. Catalyst & Molar ratio & Biodiesel yield \% & Viscosity at $\mathbf{4 0}^{\circ} \mathbf{C}$ \\
& & & $\mathbf{m m}^{2} / \mathbf{s}$ \\
\cline { 3 - 5 } & & WCO & Lard oil & WCO \\
& & (FAME) & (FAME)
\end{tabular}




\begin{tabular}{ccccccc}
\hline $\mathbf{1}$ & Sr:Al & $1: 1$ & 71.25 & 66.98 & 5.02 & 5.77 \\
& & & & & \\
\hline $\mathbf{2}$ & Sr:Al & $1: 0.51$ & 80.93 & 79.89 & 4.82 & 4.76 \\
& & & & & & \\
\hline $\mathbf{3}$ & Sr:Al & $1: 0.33$ & 85.09 & 83.41 & 4.37 & 4.56 \\
& & & & & & \\
\hline $\mathbf{4}$ & Sr:Al & $1: 0.25$ & 69.42 & 62.23 & 5.96 & 6.23
\end{tabular}

\subsection{Characterisation of catalyst}

185

186 The IR bands of Sr: $0.33 \mathrm{Al}$ and regenerated Sr: $0.33 \mathrm{Al}$ were shown in Fig. 1. The 187 spectra clearly demonstrate the intensity of the IR band and were lower in regenerated Sr: $1880.33 \mathrm{Al}$ compared to Sr: $0.33 \mathrm{Al}$. The FTIR peaks in the region of $445 \mathrm{~cm}^{-1}$ to $602 \mathrm{~cm}^{-1}$ of 189 the spectrum indicates the frequency vibrations of $\mathrm{AlO}_{6}$ groups. Moreover, the peaks 190 observed around $723 \mathrm{~cm}^{-1}$ to $872 \mathrm{~cm}^{-1}$ corresponding to the stretching and vibration of $191 \mathrm{AlO}_{4}[13,14]$. The band at $1440.64 \mathrm{~cm}^{-1}$ indicates the presence of Sr-O vibrations. The 192 bending vibrations of $\mathrm{OH}$ groups and water molecule crystallisation correspond to the IR 193 spectra of about $3,400 \mathrm{~cm}^{-1}, 3,600 \mathrm{~cm}^{-1}$ and $1,640 \mathrm{~cm}^{-1}$, respectively $[13,15]$. 

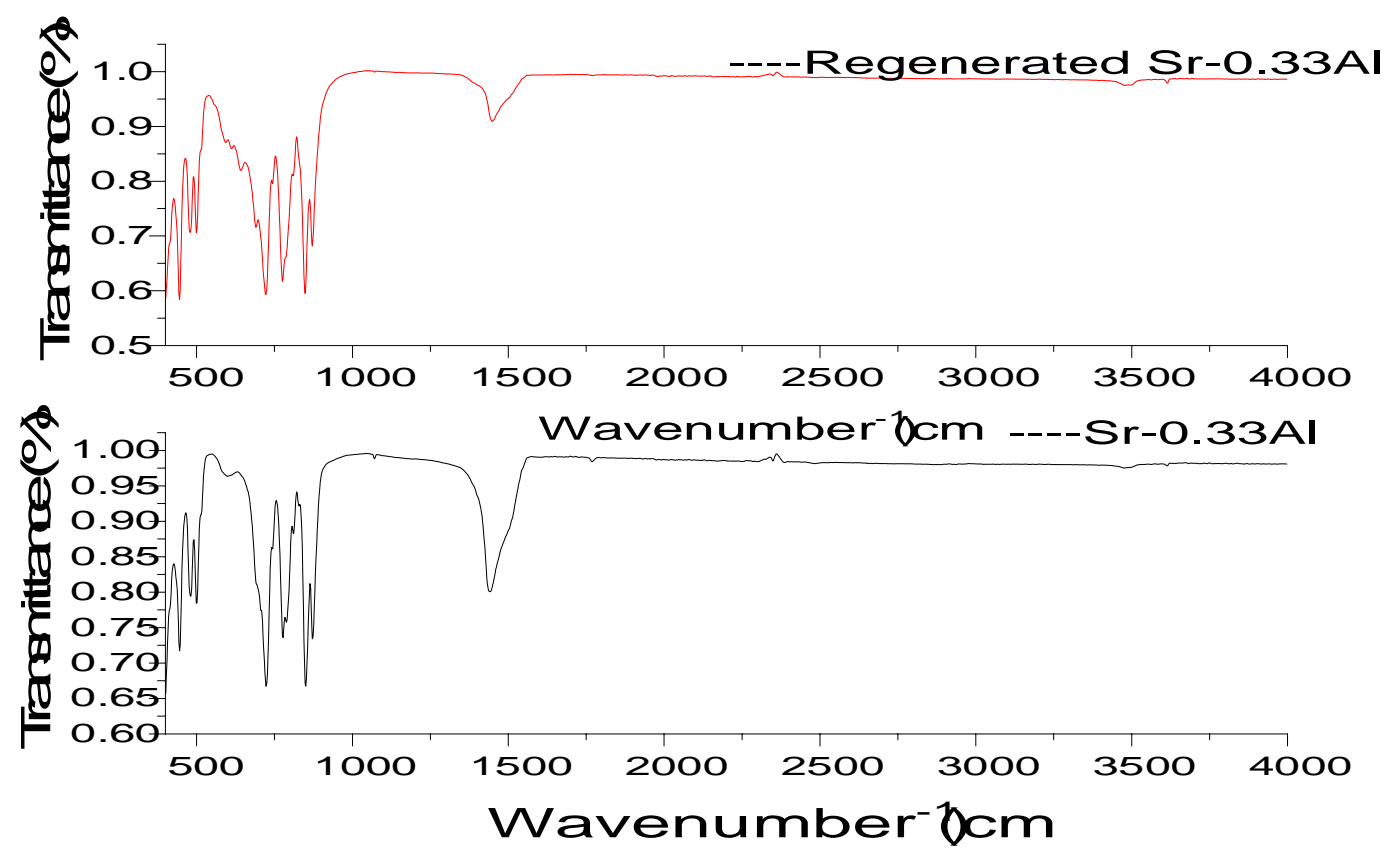

Fig. 1. FTIR spectra of Sr: $0.33 \mathrm{Al}$ and regenerated Sr: $0.33 \mathrm{Al}$

Fig. 2 shows the strong and fine XRD pattern of Sr:Al double oxides and regenerated 198 Sr:0.33Al over the $10-120^{\circ}$ attribute to the crystalline nature of the synthesised 199 nanocatalyst. The X-ray diffraction patterns at $37.1^{\circ}, 45.8^{\circ}, 56^{\circ}, 57.1^{\circ}, 58.6^{\circ}, 67.1^{\circ}$ were 200 consigned to the typical peaks of $\mathrm{Sr}_{3} \mathrm{Al}_{2} \mathrm{O}_{6}$ and show as a match to the earlier report in 201 JCPDS file No. 24-1187. The $\mathrm{Sr}_{3} \mathrm{Al}_{2} \mathrm{O}_{6}$, termed as a superstructure of the nanocatalysts, $202 \mathrm{ABO}_{3}[41]$. The less intense diffraction patterns around $18^{\circ}, 24.3^{\circ}, 29.9^{\circ}, 34.9^{\circ} 40.5^{\circ}$, $20349.9^{\circ}, 53.6^{\circ}, 60.5^{\circ}, 70.24^{\circ}$ indicate the slight existence of $\mathrm{SrCO}_{3}$ [13,16]. Concisely, the 204 diffractogram shows that a clear difference happened to $\mathrm{Sr}: 0.33 \mathrm{Al}$ after 205 transesterification. In comparison with Sr: 0.33Al, XRD patterns at $18^{\circ}, 24^{\circ}, 40.5^{\circ}, 58.6^{\circ}$ 206 and $70.2^{\circ}$ disappeared in the regenerated $\mathrm{Sr}: 0.33 \mathrm{Al}$ and the intensity of rest of the peaks 207 was reduced. This might be due to slight leaching of $\mathrm{Sr}$ and $\mathrm{Al}$ ions after reuse of the 208 catalyst. 


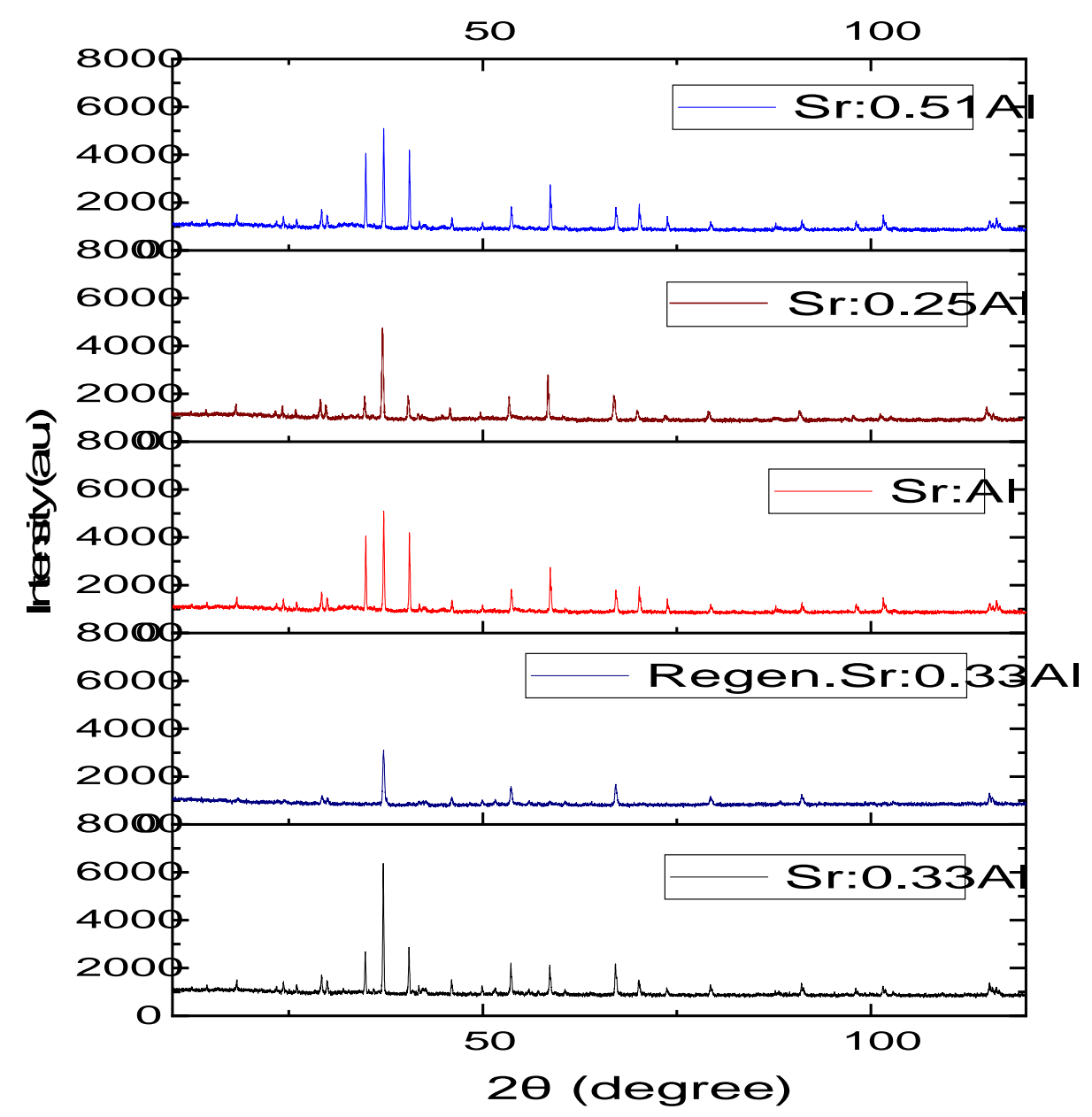

209

Fig. 2. XRD pattern of Sr: Al double oxides and regenerated Sr: 0.33Al

The SEM images of Sr: 0.33Al and regenerated Sr: 0.33Al are shown in Fig. 3, which provide information about the surface structure of the nanocatalyst and the morphological alterations which occurred to the catalyst after biodiesel production. The SEM image of Sr: 0.33Al shows more similar morphology of particles throughout the image with slight agglomeration. The minor distortion in the $\mathrm{Sr}: 0.33 \mathrm{Al}$ morphology of the catalyst is directly visible from the SEM images. The EDS graph of Sr: 0.33Al and regenerated Sr:

$2210.33 \mathrm{Al}$ shows the elemental composition of the catalyst before and after the reaction, 222 respectively. The minor variation in the composition of catalyst possibly due to slight 223 leaching of $\mathrm{Sr}$ and $\mathrm{Al}$ ions after regeneration and reuse of catalyst. 

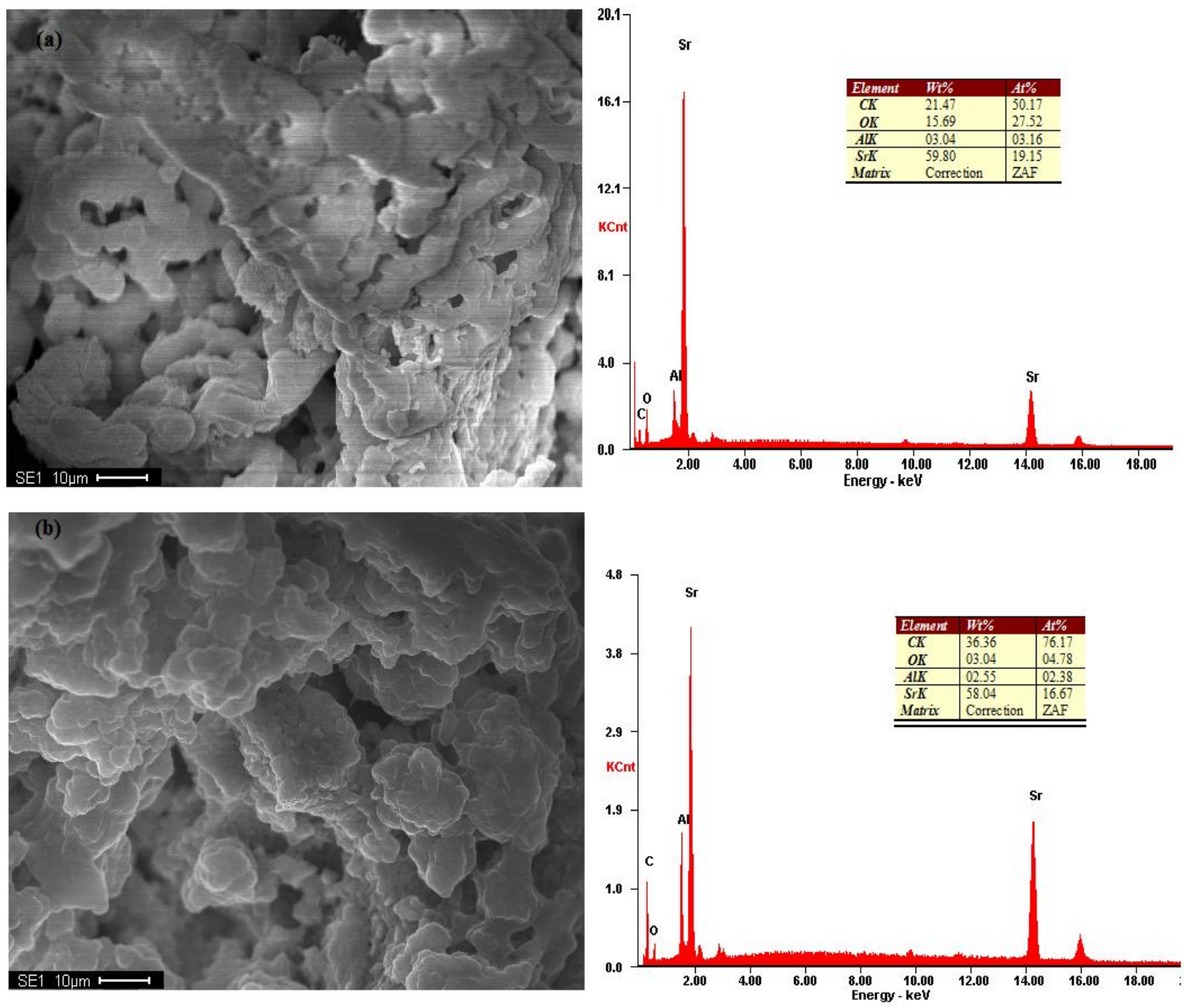

225 Fig 3. (a) SEM image and EDS of Sr: 0.33Al (b) SEM image and EDS of regenerated Sr:

$226 \quad 0.33 \mathrm{Al}$

The TEM image of Sr: 0.33Al and regenerated Sr: 0.33Al were depicted in Fig. 4a and 2304 b, respectively. The TEM images are strong agreement with the SEM results. The Sr: $2310.33 \mathrm{Al}$ and regenerated $\mathrm{Sr}: 0.33 \mathrm{Al}$ catalyst have a particle size of $57-100 \mathrm{~nm}$, which was 232 confirmed with help of TEM images. The slight variation in particle form of Sr: $0.33 \mathrm{Al}$ 233 and regenerated Sr: $0.33 \mathrm{Al}$ were also visible in TEM images. 
234

235

236

237

238

239

240

241

242

243

244

245

246

247

248
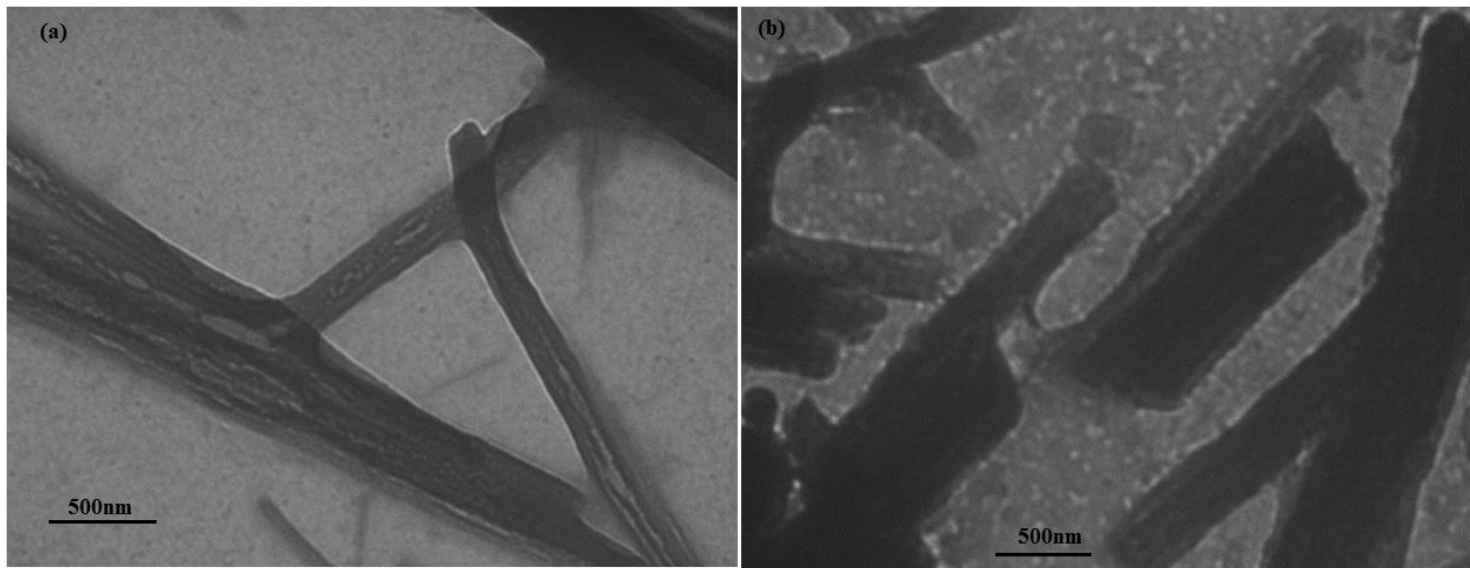

Fig. 4. TEM image of (a) Sr: 0.33Al and (b) Regenerated Sr: 0.33Al

The specific surface area, pore volume and pore size of $\mathrm{Sr}$ : $0.33 \mathrm{Al}$ and regenerated $\mathrm{Sr}$ : $0.33 \mathrm{Al}$ were summarised in Table 2 . The BET surface area and average adsorption pore width and pore volume were reduced after the reaction procedure. This result explains one of the reasons for the slight reduction in catalytic activity of the regenerated $\mathrm{Sr}$ : 0.33Al. The $\mathrm{N}_{2}$ adsorption-desorption isotherm for $\mathrm{Sr}$ : $0.33 \mathrm{Al}$ and regenerated $\mathrm{Sr}$ : $0.33 \mathrm{Al}$ from BET analysis is shown in Fig.5. The hysteresis loop of isotherm indicates the presence of mesoporous materials.

\section{Table 2.}

The results of Brunauer-Emmett-Teller surface area analysis

\begin{tabular}{|c|c|c|c|}
\hline \multicolumn{2}{|r|}{ Parameters } & Sr: & \multirow[t]{2}{*}{ Regenerated Sr: 0.33Al } \\
\hline & & $0.33 \mathrm{Al}$ & \\
\hline \multirow{3}{*}{$\begin{array}{l}\text { Surface } \\
\text { area }\end{array}$} & BET surface area $\left(\mathrm{m}^{2} / \mathrm{g}\right)$ & 0.95 & 0.50 \\
\hline & $\begin{array}{l}\text { BJH adsorption cumulative surface area of } \\
\text { pores }\left(\mathrm{m}^{2} / \mathrm{g}\right)\end{array}$ & 0.49 & 0.20 \\
\hline & $\begin{array}{l}\text { BJH desorption cumulative surface area of } \\
\text { pores }\left(\mathrm{m}^{2} / \mathrm{g}\right)\end{array}$ & 0.60 & 0.26 \\
\hline
\end{tabular}




\begin{tabular}{|c|c|c|c|}
\hline \multirow[t]{3}{*}{$\begin{array}{l}\text { Pore } \\
\text { volume }\end{array}$} & $\begin{array}{l}\text { Single point adsorption total pore volume } \\
\text { of pores }\left(\mathrm{cm}^{3} / \mathrm{g}\right)\end{array}$ & 0.002 & 0.0009 \\
\hline & $\begin{array}{l}\text { BJH adsorption cumulative volume of } \\
\text { pores }\left(\mathrm{cm}^{3} / \mathrm{g}\right)\end{array}$ & 0.0052 & 0.0027 \\
\hline & $\begin{array}{l}\text { BJH desorption cumulative volume of } \\
\text { pores }\left(\mathrm{cm}^{3} / \mathrm{g}\right)\end{array}$ & 0,0056 & 0.0030 \\
\hline \multirow[t]{3}{*}{ Pore size } & Adsorption average pore width (nm) & 8.5 & 6.2 \\
\hline & $\begin{array}{l}\text { BJH adsorption average pore diameter } \\
(\mathrm{nm})\end{array}$ & 43.1 & 53.2 \\
\hline & $\begin{array}{l}\text { BJH desorption average pore diameter } \\
(\mathrm{nm})\end{array}$ & 37.1 & 44.8 \\
\hline
\end{tabular}

249

250

251

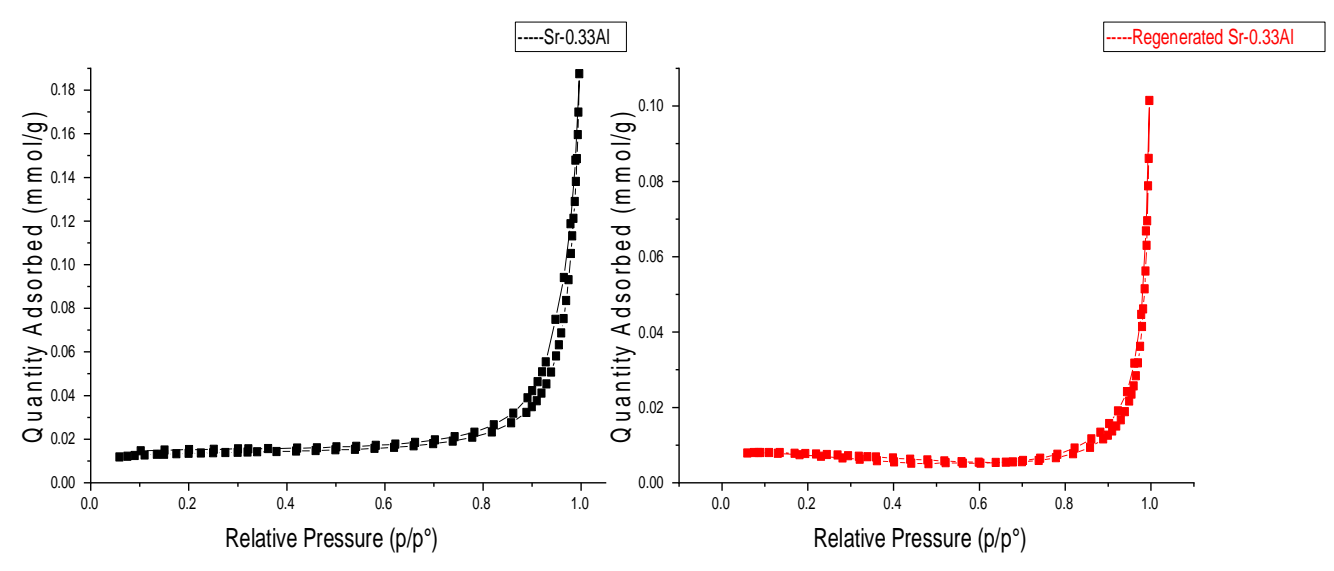

252

253

254

255 Fig. 5. $\mathrm{N}_{2}$ adsorption-desorption isotherm plot of $\mathrm{Sr}$ : $0.33 \mathrm{Al}$ and regenerated $\mathrm{Sr}$ :

$256 \quad 0.33 \mathrm{Al}$

257 
260 XPS was applied to examine the surface properties and binding energies (BE) of 261 elements in Sr-Al double oxides. The chemical environment of $\mathrm{Sr}, \mathrm{Al}, \mathrm{O}, \mathrm{C}$ were 262 simulated by Gaussian curve-fitting of the $\mathrm{Sr} 3 \mathrm{~d}, \mathrm{Al} 2 \mathrm{p}, \mathrm{O}$ 1s and C 1s spectra. Fig. 6 (a) 263 and (b) depicts XPS fitted spectra of Sr: 0.33Al and the regenerated Sr: $0.33 \mathrm{Al}$ 264 nanocatalyst. The Sr-Al double oxides depicts Sr3d signals with two peaks at binding 265 energies of 133.1 and $134.9 \mathrm{eV}$ assigned to $\mathrm{Sr} 3 \mathrm{~d}_{5 / 2}$ and $3 \mathrm{~d}_{3 / 2}$, respectively[17]. The $\mathrm{Al} 2 \mathrm{p}$ 266 spectra of $\mathrm{Sr}: 0.33 \mathrm{Al}$ and regenerated $\mathrm{Sr}$ : $0.33 \mathrm{Al}$ shows binding energy at $73 \mathrm{eV}$, which 267 corresponds to pure Al. The pure Al helps in the formation of defective oxides that helps 268 in trapping charges [18]. The presence of weakly adsorbed oxygen, stronger binding with 269 adsorbed oxygen and aluminium atoms was described by a signal at $531 \mathrm{eV}$ represented 270 in $\mathrm{O} 1 \mathrm{~s}$ spectra of $\mathrm{Sr}: 0.33 \mathrm{Al}$ and regenerated $\mathrm{Sr}: 0.33 \mathrm{Al}$ correspondingly [19]. The 271 binding energies at $284.6 \mathrm{eV}$ and $289 \mathrm{eV}$ in $\mathrm{C} 1 \mathrm{~s}$ core level spectrum of Sr: $0.33 \mathrm{Al}$ 272 consigned to $\mathrm{C}-\mathrm{C}, \mathrm{C}=\mathrm{O}$ respectively. Furthermore, the $\mathrm{C} 1 \mathrm{~s}$ spectra of regenerated Sr: $2730.33 \mathrm{Al}$ indicates only the presence of $\mathrm{C}-\mathrm{C}$ binding energies [20, 21]. 

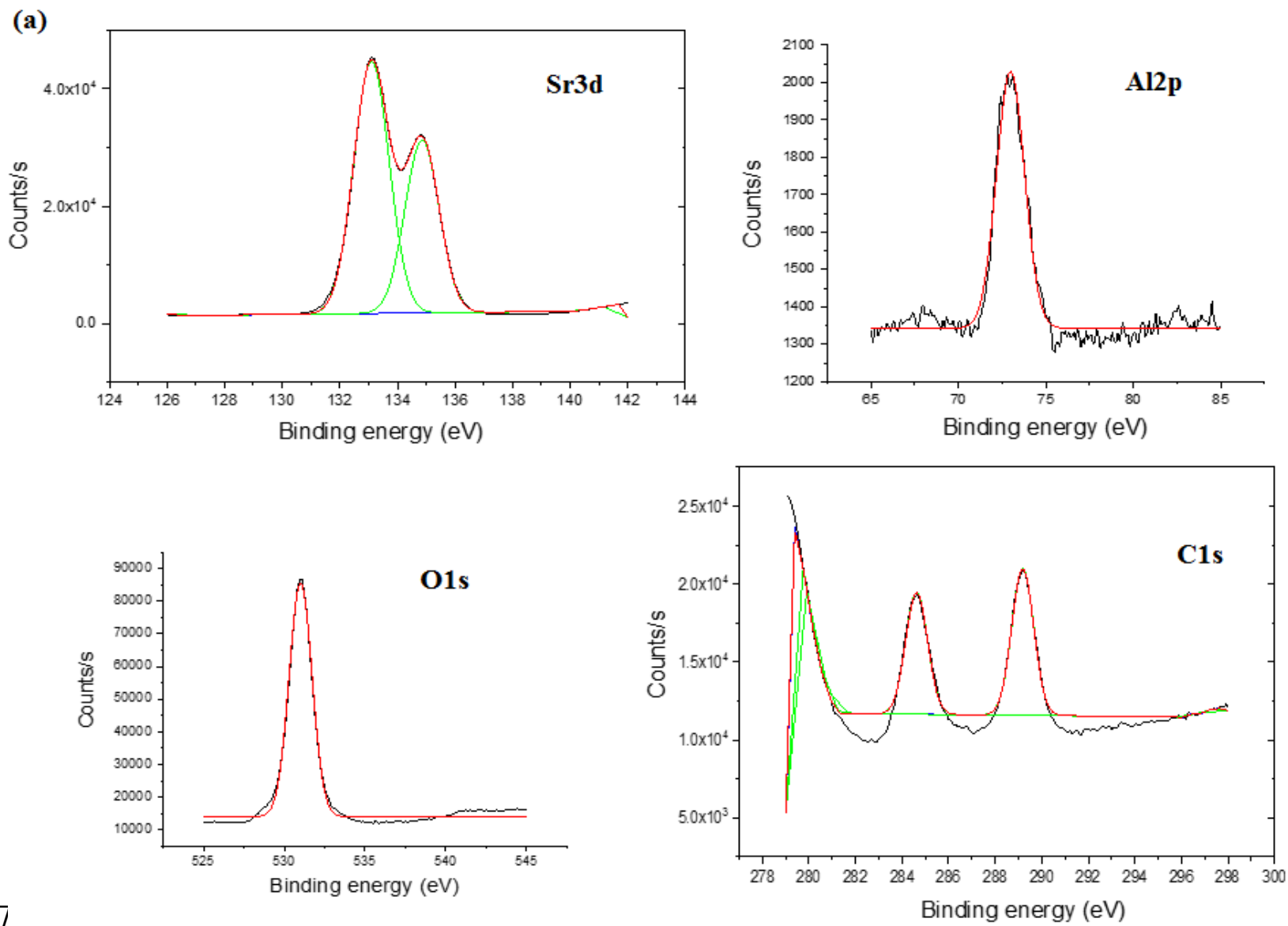

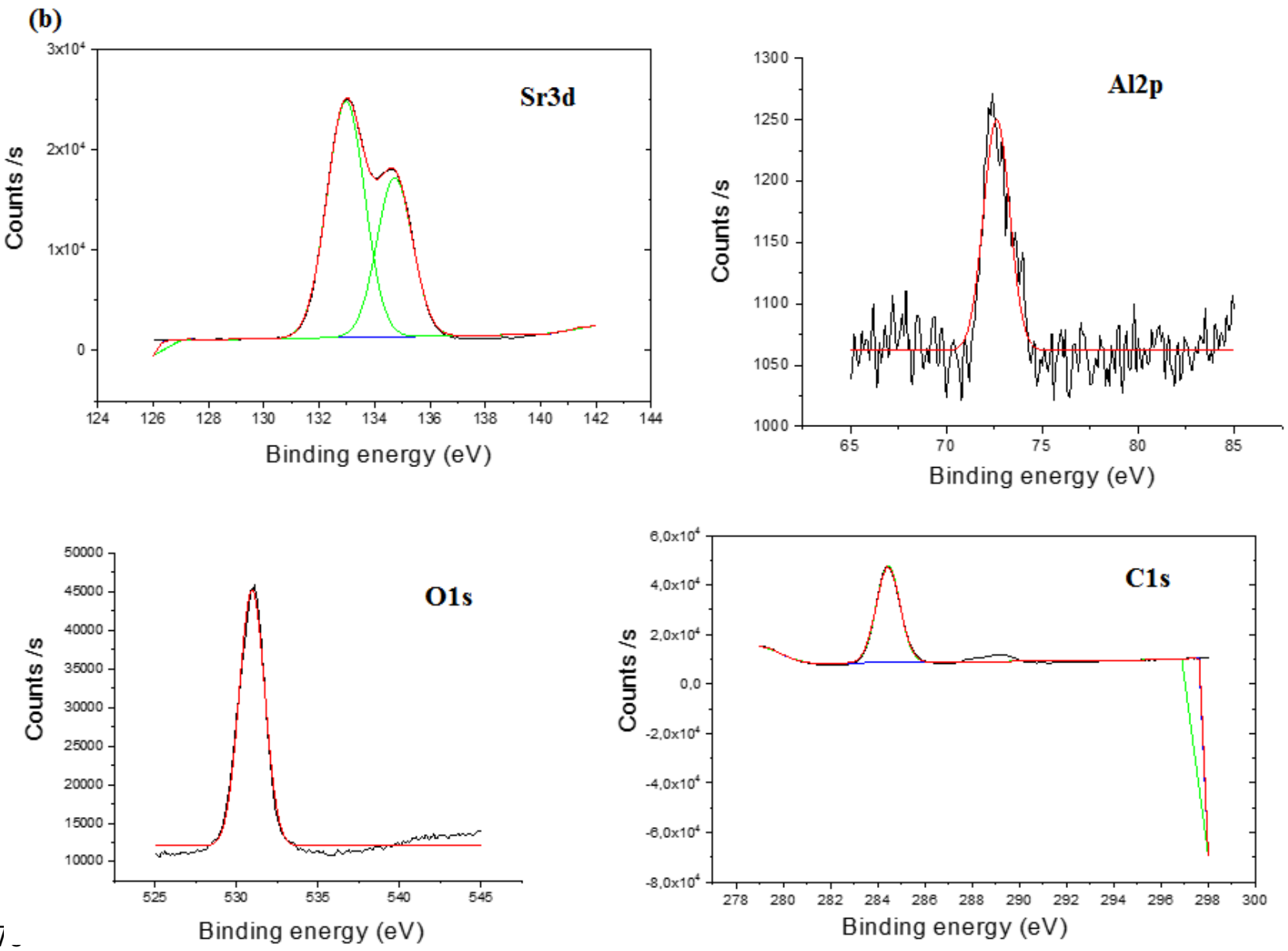

Fig. 6. XPS spectra of (a) bare Sr: $0.33 \mathrm{Al}$ and (b) regenerated $\mathrm{Sr}$ : $0.33 \mathrm{Al}$ nanocatalyst

\subsection{Characterisation of biodiesel}

The fatty acid methyl esters made from the lard oil and WCO were characterised by

284 GC-MS, ${ }^{1} \mathrm{H}$ NMR and ${ }^{13} \mathrm{C}$ NMR. The quality of the produced biodiesel should satisfy the criteria determined by ASTM/EN 14214 limits.

287 The chemical composition of biodiesel was demonstrated with the help of GC-MS 288 chromatogram and National Institute of Standards and Technology (NIST) 2014 MS 289 library. The fatty acid methyl esters obtained after the transesterification of lard oil and 290 waste cooking oil with Sr: 0.33Al illustrated in Fig 7. Each FAME peak in the sample 
291

292

293

294

295

296

297

298

299

300

301

302
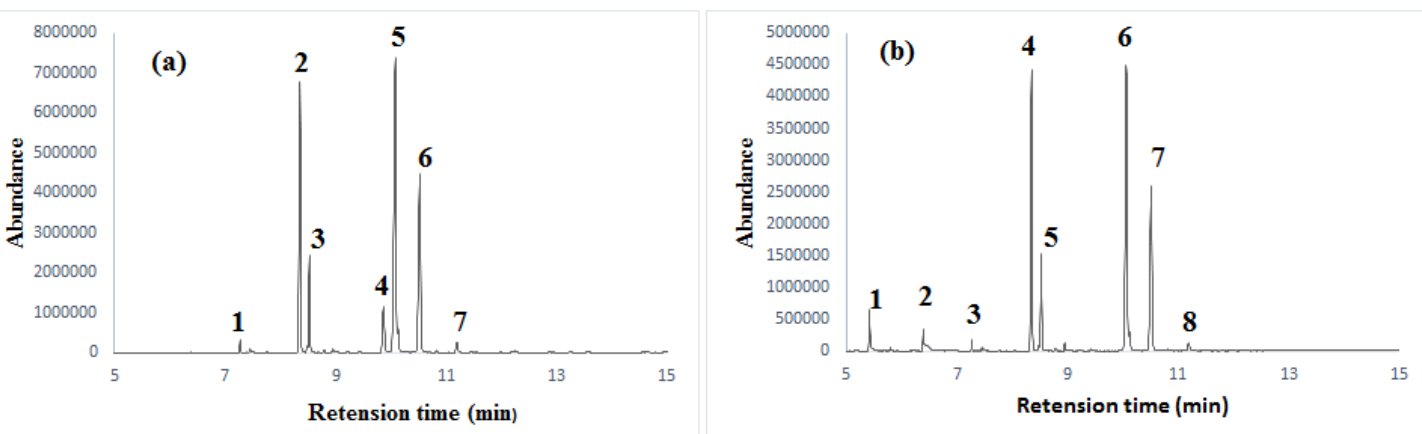

Fig. 7. Illustrates the GC-MS spectrum of biodiesel obtained from (a) lard oil and (b) waste cooking oil, after transesterification with $0.6 \mathrm{wt} \mathrm{Sr}: 0.33 \mathrm{Al}, 1: 4.5$ oil to the methanol molar ratio at $40^{\circ} \mathrm{C}$ for $30 \mathrm{~min}$.

\section{Table 3.}

The composition of biodiesel obtained after transesterification with Sr: 0.33Al.

303

304

Peak

Lard oil FAME

\section{Compound name}

Retention time
$(\min )$

\begin{tabular}{cccc}
\hline $\mathbf{1}$ & 7.3 & 92.6 & methyl 12-methyltridecanoate \\
\hline $\mathbf{2}$ & 8.4 & 91.5 & methyl hexadecanoate \\
\hline $\mathbf{3}$ & 8.5 & 94.4 & methyl (Z)-hexadec-9-enoate \\
\hline $\mathbf{4}$ & 9.9 & 93.5 & methyl octadecanoate \\
\hline $\mathbf{5}$ & 10.1 & 96 & methyl (E)-octadec-13-enoate \\
\hline $\mathbf{6}$ & 10.5 & 96.5 & methyl (11E,14E)-octadeca-11,14-dienoate \\
\hline
\end{tabular}




\begin{tabular}{|c|c|c|c|}
\hline & $\begin{array}{l}\text { Retention time } \\
\quad(\min )\end{array}$ & $\begin{array}{l}\text { Library match } \\
\qquad(\%)\end{array}$ & \\
\hline 1 & 5.4 & 89.9 & methyl decanoate \\
\hline 2 & 6.4 & 84.6 & methyl dodecanoate \\
\hline 3 & 7.3 & 92.9 & methyl 12-methyltridecanoate \\
\hline 4 & 8.4 & 90.3 & methyl hexadecanoate \\
\hline 5 & 8.8 & 85 & methyl 14-methylpentadecanoate \\
\hline 6 & 10.1 & 96.8 & methyl (E)-octadec-13-enoate \\
\hline 7 & 10.5 & 96.4 & methyl (11E,14E)-octadeca-11,14-dienoate \\
\hline 8 & 11.2 & 93.2 & ethyl (9Z,12Z,15Z)-octadeca-9,12,15-trienoat \\
\hline
\end{tabular}

The yield of fatty acid methyl esters derived from lard and waste cooking oil was 308 estimated using ${ }^{1} \mathrm{H}$ and ${ }^{13} \mathrm{C}$ NMR spectroscopy. The conversion was calculated using 309 equation 2, which was already mentioned hereinabove. With the help of ${ }^{1} \mathrm{H}$ NMR, FAME 310 percentage of sample obtained after transesterification of lard oil and waste cooking oil 311 with Sr: $0.33 \mathrm{Al}$ was found to be $99.7 \%$ and $99.4 \%$ correspondingly. Fig. 8a and 8 b 312 demonstrates the ${ }^{1} \mathrm{H}$ NMR spectrum of fatty acid methyl esters sample obtained from lard 313 and waste cooking oil with help of Sr: 0.33Al as catalyst, respectively. It helps to 314 characterise FAME and can be used to conform the existence of methyl esters in the 315 biodiesel.

In ${ }^{1} \mathrm{H}$ NMR, the signal at $3.63 \mathrm{ppm}$ indicates methoxy group (A $\left.\mathrm{ME}\right)$ of FAME and 318 signal at $2.27 \mathrm{ppm}$ corresponding to the methylene group $\left(\mathrm{A}_{\mathrm{CH} 2}\right)$. The presence of these 319 signal in the biodiesel sample verifies the presence of methyl ester. Apart from the signal 320 used for the quantification, there are other identifiable peaks such as the signal at 0.83 to 
$3210.86 \mathrm{ppm}$ for $\mathrm{CH}_{2}-\mathrm{CH}_{3}$ or for latter methyl group. The peaks in the range of 1.22 to 2.3

322 represents $\mathrm{CH}_{2}$ (methylene group). The signals at 5.3 range indicates the presence of $323 \mathrm{CH}=\mathrm{CH}$ (double bond) groups or olefinic groups [22, 23] The 3.45ppm corresponds to 324 solvent residual signal[42]. Fig S1 (a) and S1 (b) represents ${ }^{13} \mathrm{C}$ NMR spectra of biodiesel 325 obtained after transesterification of lard and waste oil with $\mathrm{Sr}$ : $0.33 \mathrm{Al}$ as nanocatalyst. In $326{ }^{13} \mathrm{C} \mathrm{NMR}$, the signal in the range of $174 \mathrm{ppm}$ and $51 \mathrm{ppm}$ indicates the existence of ester 327 carbonyl - $\mathrm{COO}$ - and $\mathrm{C}-\mathrm{O}$, respectively. The unsaturation in biodiesel sample was 328 confirmed with help of signals over the ppm range 126-132 ppm. The presence of the $329 \mathrm{CH}_{2}$ group was shown with the help of the signals in the region of 21-35 ppm [23]The 330 peaks 0-55 ppm corresponds to aliphatic carbon in fatty acid esters $[43,44]$.

331

(a)

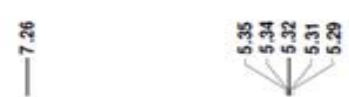

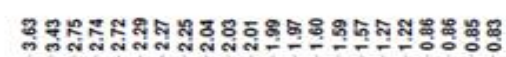

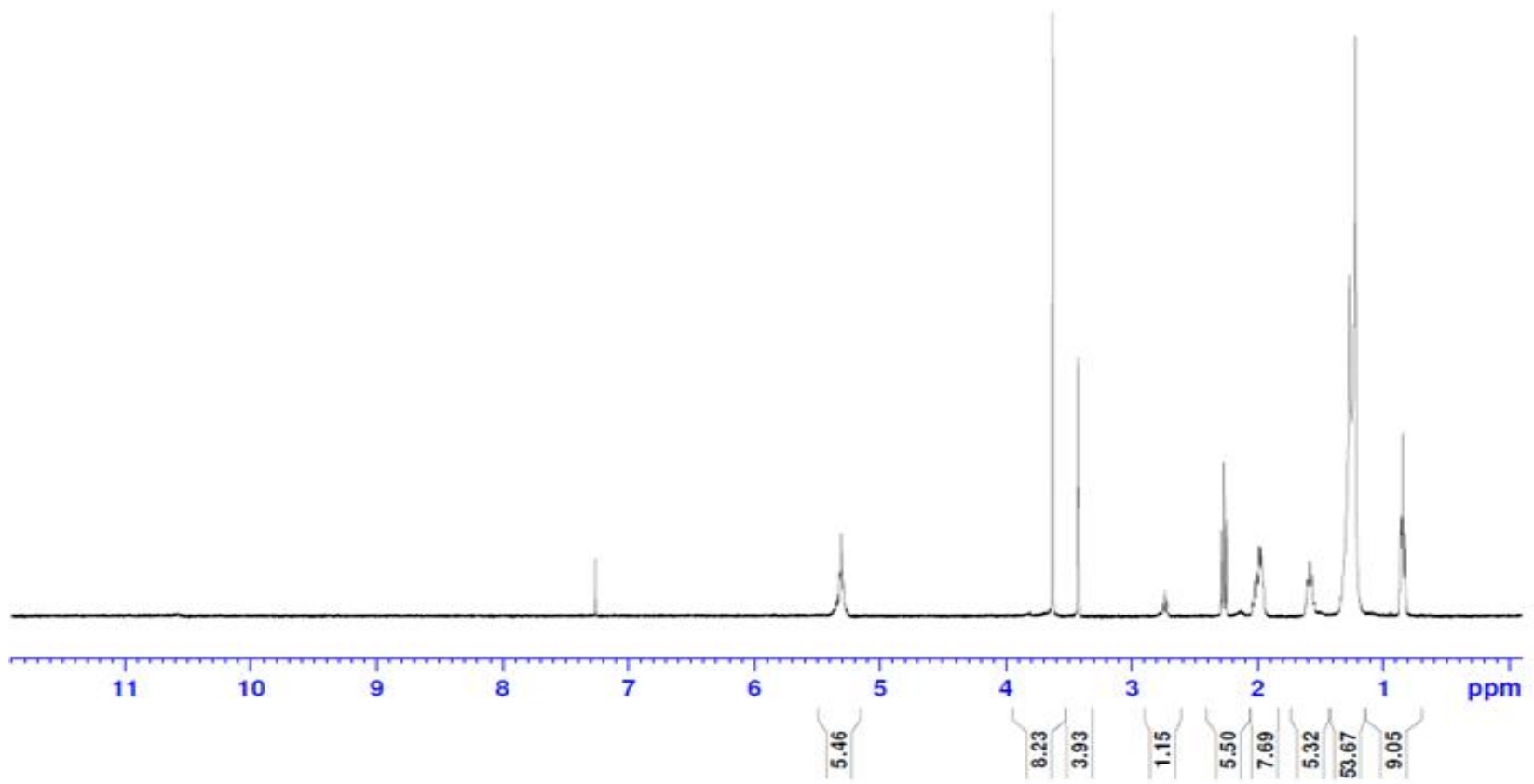


(b)

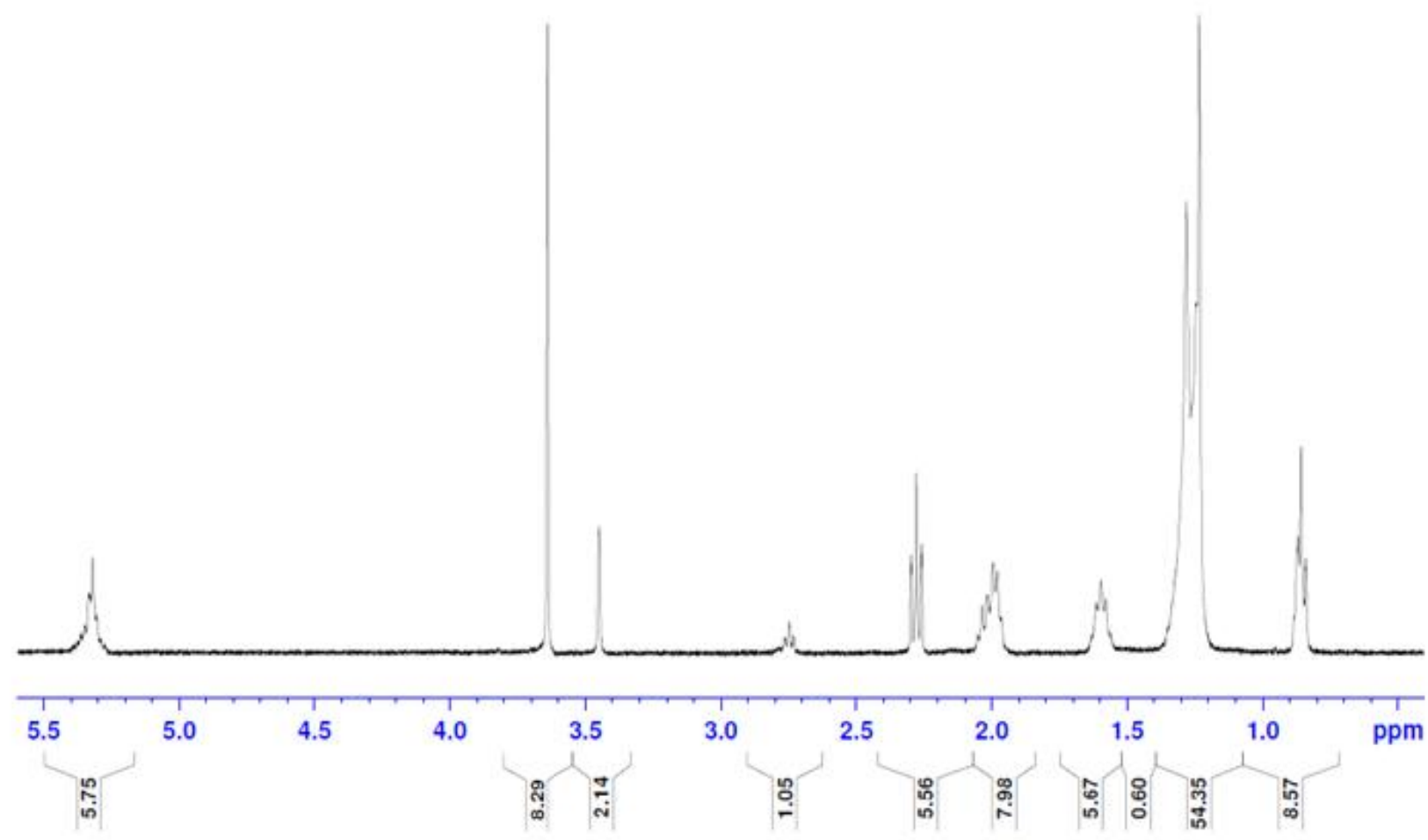

339 Fig. 8 b. The ${ }^{1} \mathrm{H}$ NMR for the biodiesel sample obtained from waste cooking oil with Sr:

$340 \quad 0.33 \mathrm{Al}$

\subsection{Influence of various parameters on biodiesel production}

The higher yield of biodiesel was achieved by optimising the reaction conditions such 346 as the amount of co-solvent, oil to methanol ratio, reaction temperature, reaction time and catalyst amount. Based on the preliminary screening of catalysts, the Sr: $0.33 \mathrm{Al}$ catalyst was found to be a more capable catalyst for the conversion of lard and waste cooking oil to biodiesel. A series of transesterification reactions were performed using Sr: $0.33 \mathrm{Al}$ and optimised in order to achieve the reaction parameters for optimisation. 


\subsubsection{Effect of various co-solvents on biodiesel production}

Fig 9. (a) shows the influence of various co-solvent on biodiesel production from different oils. The quantity of co-solvent varied over the range of 5-20 wt $\%$ based on the weight of oil used for the transesterification reaction. Based on reported studies cosolvent enhance interaction between reactants in presence of minimum amount of catalyst and oil to methanol ratio[8-10]. Therefore slightly higher theoretical minimum of oil to methanol ratio is used to determine effect of co-solvent on transesterification reaction. The evaluation of the effect of the co-solvent on the biodiesel production procedure was attained by performing the transesterification of each oil at $40^{\circ} \mathrm{C}$ by using $0.6 \mathrm{wt} \%$ catalyst and 1:3.5 oil to the methanol molar ratio for $40 \mathrm{~min}$ in the presence of various weight percentage of acetone and THF, respectively. Generally, the co-solvent helps to increase the miscibility of reactants in a transesterification reaction and thereby results in a higher yield of fatty acid methyl esters. On the contrary, a larger amount of co-solvent above the optimum value hinders the phase separation of biodiesel and glycerol [8-10]. In the present study, it was observed that the samples with $5 \mathrm{wt} \%$ of THF resulted in the maximum yield of FAME from both lard and waste cooking oil. This can be interpreted to means $5 \mathrm{wt} \%$ of THF is enough and efficient to enhance the following factors such as the solubility of methanol and oil, phase separation of FAME and glycerol and for separation of glycerol from reaction mixture.

\subsubsection{Effect of temperature on biodiesel production}

The influence of temperature on transesterification reaction was investigated by conducting a reaction at various temperatures using $0.9 \mathrm{wt} \%$ catalyst, $5 \mathrm{wt} \%$ THF, 1:5.5 oil to methanol molar ratio for 45 min reaction time (Fig. 9b). The temperature range chosen for the reaction was lower than the boiling point of THF. The yield of biodiesel from lard oil and WCO increased gradually up to $99.7 \%$ and $99.4 \%$ at $50^{\circ} \mathrm{C}$ and $60^{\circ} \mathrm{C}$, respectively, and resulted in the maximum yield of fatty acid methyl esters. Moreover, the temperature has a direct effect on the rate of the reaction but elevation in temperature 
384 after the optimum value decreases the yield of biodiesel which is due to the fact that an 385 elevated temperature favours methanol or co-solvent vaporisation $[10,24,25]$. Further experiments were conducted at $50^{\circ} \mathrm{C}$ and $60^{\circ} \mathrm{C}$ for lard and $\mathrm{WCO}$, respectively.

\subsubsection{Effect of the reaction time on biodiesel production}

The effect of the reaction time on the transesterification reaction of lard oil and WCO was observed by executing reactions for various time intervals using $0.9 \mathrm{wt} \%$ catalyst, 1:5.5 oil to methanol molar ratio at $50^{\circ} \mathrm{C}$ and $60^{\circ} \mathrm{C}$ correspondingly were depicted in Fig. 9c. The present investigation was employed to represent the effect of THF on the rate of the transesterification reaction. The fatty acid methyl ester content rose with the increase in reaction time and reached its maximum with a shorter interval of time in the reaction mixtures with the co-solvent. This is due to the reduction of the phase boundary in reactants and a faster separation of biodiesel and glycerol.

\subsubsection{Effect of the catalyst amount (weight\%) in biodiesel production}

400

401

Fig 9d was applied to determine the effect of the catalyst concentration on biodiesel 402 production by performing reactions at various catalyst concentration from $0.2 \%$ to 1.2 $\mathrm{wt} \%$ of oil. The $99.7 \%$ and $99.4 \%$ of biodiesel yield was obtained from lard oil and waste cooking oil using $0.9 \mathrm{wt} \%$ catalyst, $5 \mathrm{wt} \%$ THF as the co-solvent and 1:5.5 oil to methanol molar ratio within $45 \mathrm{~min}$ of the reaction time at $50^{\circ} \mathrm{C}$ and $60^{\circ} \mathrm{C}$ correspondingly. The conversion of oil to biodiesel raises with an increase in the amount of catalyst up to 0.9 $\mathrm{wt} \%$ and extra rise in the catalyst concentration beyond the optimum value showed reduction in biodiesel yield due to a decrease in the availability of active sites and hindrance to phase separation $[9,26,27]$.

\subsubsection{Effect of oil to methanol ratio in biodiesel production}

The biodiesel conversion significantly increases as oil to methanol molar ratios were 
416 transesterification process was carried out with $0.9 \mathrm{wt} \%$ catalyst for $45 \mathrm{~min}$ of reaction

417 time at $50^{\circ} \mathrm{C}$ and $60^{\circ} \mathrm{C}$, respectively. The biodiesel yield was negatively affected by a

418 rising methanol concentration above the optimum amount (1:5.5) which was due to the

419 higher solubility of glycerol to ester phase resulting in difficulty for the separation of

420 biodiesel. It may also support a reverse reaction than the production of biodiesel [28, 29].

421
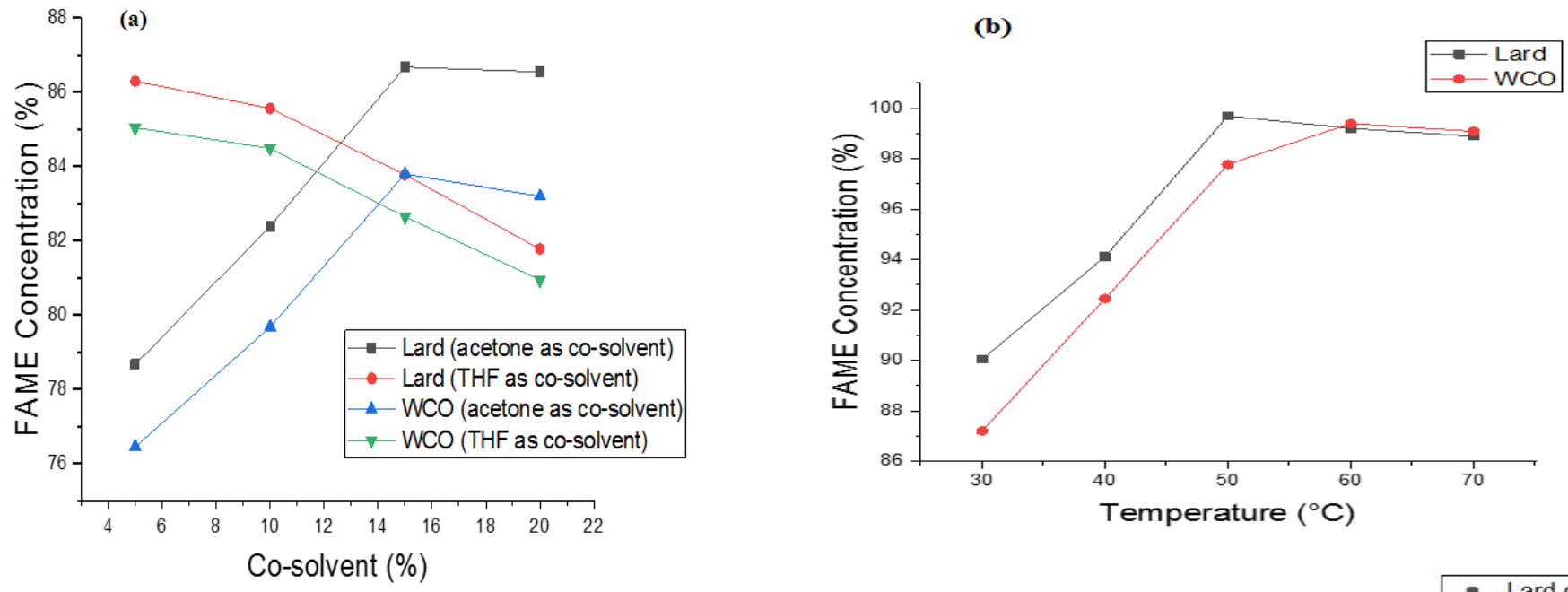

(c)
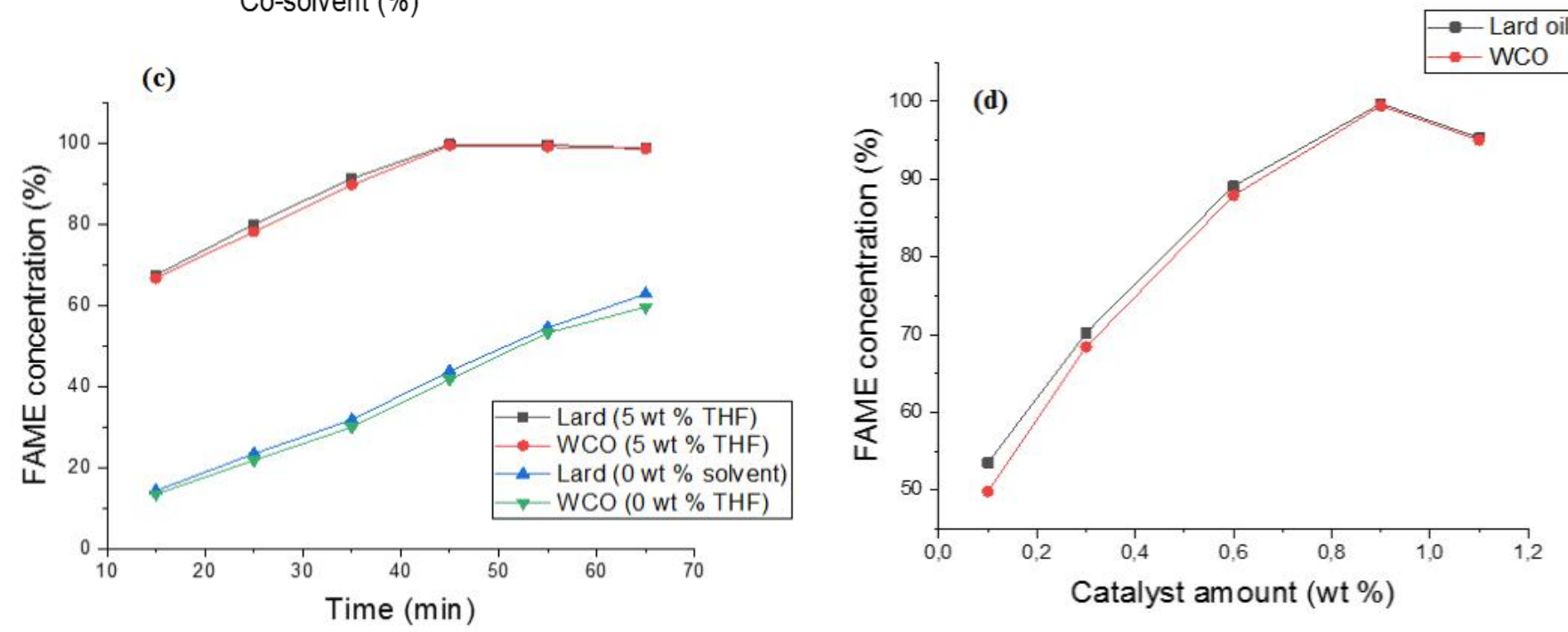

424 


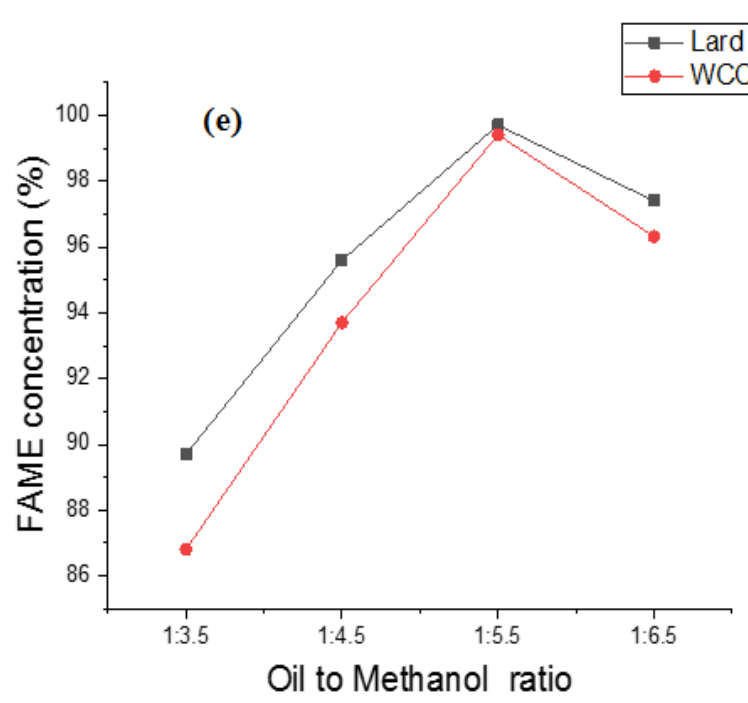

Fig. 9. (a). Effect of various co-solvents on the biodiesel yield (b). Effect of the reaction temperature on the biodiesel yield (c). Effect of the reaction time on the biodiesel yield (d) Effect of the catalyst amount (weight \%) on the biodiesel yield (e) Effect of the oil to methanol molar ratio on the biodiesel yield.

441

\subsection{Properties of synthesised biodiesel}

The properties of fatty acid methyl esters were determined using the EN 14214/ASTM D6751 method as shown in Table 4. All of these features play a key role in the biodiesel quality. The acid value of lard oil methyl ester and WCO methyl ester were found to be

$4470.29 \mathrm{mg} \mathrm{KOH} / \mathrm{g}$ and $0.31 \mathrm{mg} \mathrm{KOH} / \mathrm{g}$, respectively. The resulted acid values were within 448 the limits of the European International standard organisation (EN ISO) method. The 449 increase in acid value can result in difficulties like corrosion of rubber parts of engine and 450 filter clogging [30]. The density and kinematic viscosity are other two main fuel features 451 that influence the fuel injection operation. Higher values of these factors can negatively 452 affect the fuel injection process and leads in the formation of engine deposits [31, 32].

453 The density and kinematic viscosity of both methyl esters were within EN ISO 12185 and 454 EN ISO 3104 limits correspondingly. The other factor is flash point, which specifies the 455 minimum temperature at which fuel starts to ignite. It is vital to know the flash point value 456 for fuel handling and storage [33]. Cloud point is important when fuel is exposed to lower 
temperature where as cetane number directly connects to quality of fuel. The rest of the

458 preferred features such as calorific value, cloud point, cetane number, and pour point are 459 also within EN ISO/ASTM limits.

460

Table 4.

462

Properties of fatty acid methyl esters from different feedstocks

\begin{tabular}{|c|c|c|c|c|}
\hline Property & $\begin{array}{l}\text { EN 14214/ } \\
\text { ASTM D6751 } \\
\text { test method }\end{array}$ & Limits & $\begin{array}{l}\text { Methyl ester } \\
\text { from Lard oil }\end{array}$ & $\begin{array}{l}\text { Methyl } \\
\text { ester from } \\
\text { WCO }\end{array}$ \\
\hline $\begin{array}{l}\text { Acid value (mg } \\
\mathrm{KOH} / \mathrm{g})\end{array}$ & Pr EN14104 & $0.5 \max$ & 0.29 & 0.31 \\
\hline $\begin{array}{l}\text { Density at } 15^{\circ} \mathrm{C} \\
\left(\mathrm{kg} / \mathrm{m}^{3}\right)\end{array}$ & EN ISO 12185 & $860-900$ & 882.1 & 885.6 \\
\hline $\begin{array}{l}\text { Kinematic } \\
\text { viscosity at } 40^{\circ} \mathrm{C} \\
\mathrm{mm}^{2} / \mathrm{s}\end{array}$ & EN ISO 3104 & $3-5$ & 3.98 & 4.01 \\
\hline $\begin{array}{l}\text { Calorific value } \\
(\mathrm{MJ} / \mathrm{kg})\end{array}$ & D6751 & & 39.92 & 40.45 \\
\hline Flash point $\left({ }^{\circ} \mathrm{C}\right)$ & EN ISO 2719 & - & $131^{\circ} \mathrm{C}$ & $138^{\circ} \mathrm{C}$ \\
\hline Cetane number & EN ISO 5165 & $\geq 51$ & 63 & 67 \\
\hline Cloud point $\left({ }^{\circ} \mathrm{C}\right)$ & D2500 & & 8 & 9 \\
\hline Pour point $\left({ }^{\circ} \mathrm{C}\right)$ & ISO 3016 & & 5 & 7 \\
\hline
\end{tabular}

\subsection{Reusability of catalyst}

466

467 The concept of catalyst reusability plays a vital role in an environmentally friendly 468 biodiesel production process. Therefore, the catalyst recovered after the 469 transesterification reaction was subjected to a cleaning process to remove the deposited 470 oil, products or glycerol. The cleaning of the catalyst with a suitable solvent and 471 calcination helps in its regeneration $[11,34]$. The catalytic reusability of the Sr-0.25Al 472 nanocatalyst was analysed by the separation of the catalyst from fatty acid methyl esters 
473 and glycerol. The catalytic reusability Sr: 0.33Al over lard oil and waste cooking oil using

$4740.9 \mathrm{wt} \%$ catalyst, $5 \mathrm{wt} \%$ THF as co-solvent and 1:5.5 oil to methanol molar ratio within

$47545 \mathrm{~min}$ of reaction time at $50^{\circ} \mathrm{C}$ and $60^{\circ} \mathrm{C}$ correspondingly depicted in Fig. 10. Lard oil

476 and WCO biodiesel yields were decreased from $99.7 \%$ to $95.1 \%$ and $99.4 \%$ to $93.7 \%$,

477 respectively, in four cycles. Compared to other reported studies the current catalyst

478 showed higher stability and better biodiesel yield even after five cycles of reaction[11,26,

$47938,39,40]$. The minor changes in the catalyst structure and composition, reduction in BET

480 surface area illustrated in catalyst characterisation findings agrees with the drop in

481 catalytic activity. The reusability test showed that the regenerated catalyst was quite

482 efficient even after four cycles with the significant conversion of oil into biodiesel. The

483 nanocatalyst stability after various cycles were evaluated based on the the leached metal

484 ion concentration. The Agilent 5110 Inductively coupled plasma (ICP) was used to

485 measure metal concentration. It was detected that from cycle 1 to cycle 5, the $\mathrm{Al}$ and $\mathrm{Sr}$

486 concentrations in solution were less than 0.0072 and $0.024 \mathrm{mg} / \mathrm{L}$.

487

488

489

490

491

492

493

494
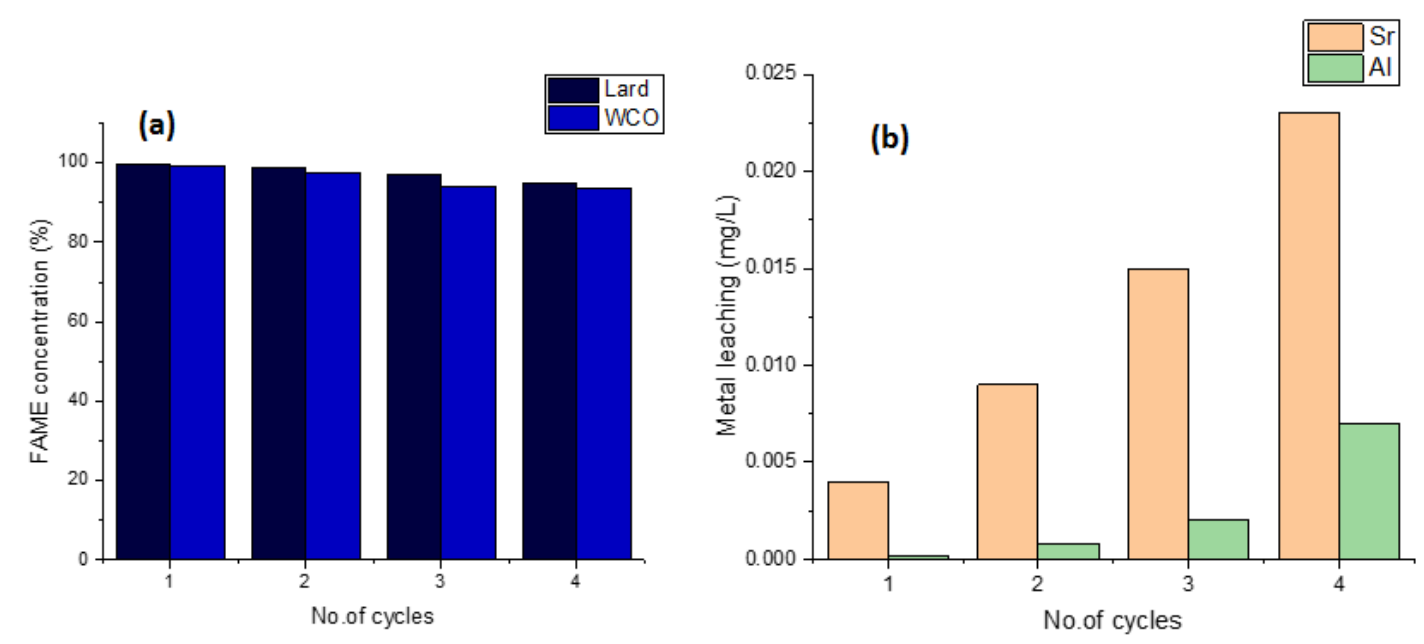

Fig. 10. (a) Reusability analysis of Sr: $0.33 \mathrm{Al}$ catalyst and (b) Stability of Sr: 0.33Al catalyst up to four transesterification reactions

\section{Conclusion}


The $\mathrm{Sr}-\mathrm{Al}$ doubleoxides were synthesised and employed for the transesterification reaction of lard and waste cooking oil to biodiesel. The influence of acetone and THF as

497 a co-solvent on biodiesel production were investigated. The combined effect of a co498 solvent and nanocatalyst on lard and waste cooking oil were examined. The best catalytic 499 activity was attained with $\mathrm{Sr}$ : $0.33 \mathrm{Al}$ as a nanocatalyst and THF as a co-solvent. The 500 characterisation of synthesised catalyst and regenerated catalyst were performed by FTIR, 501 XRD, SEM, TEM, XPS and BET. It helps to determine the morphology, composition and 502 stability of the catalyst before and after the transesterification reaction. The factors 503 affecting biodiesel production were optimised. The maximum yield of $99.7 \%$ and $99.4 \%$ 504 of lard oil methyl ester and WCO biodiesel was observed with 5 wt $\%$ THF, 0.9 wt $\%$ 505 catalyst amount, 1:5.5 oil to methanol ratio with in a reaction time of 45 minutes at $50^{\circ} \mathrm{C}$ 506 and $60^{\circ} \mathrm{C}$, respectively. The presence of the co-solvent increases the reaction rate and 507 reduction in methanol consumption compared to the usual transesterification reaction.

508 The reusability of the catalyst also exhibited a favourable result, which makes it cost 509 effective and eco-friendlier. The properties of biodiesel such as acid value, density, 510 kinematic viscosity and flash point were within the EN 14214 limits. All these results 511 summarise the efficiency of $\mathrm{Sr}-\mathrm{Al}$ nanocatalysts as a potential catalyst and THF as a better 512 co-solvent for the production of superior quality biodiesel from different feedstock.

\section{$513 \quad$ References}

515 [1] J. Hossain, Bio-Diesel from Mustard Oil: A Renewable Alternative Fuel for Small 516 Diesel Engines, Mod. Mech. Eng. 1 (2011) 77-83. doi:10.4236/mme.2011.12010.

[4] I. Thushari, S. Babel, Bioresource Technology Sustainable utilization of waste 525

[2] L. Wen, Y. Wang, D. Lu, S. Hu, H. Han, Preparation of KF/CaO nanocatalyst and its application in biodiesel production from Chinese tallow seed oil, Fuel. 89 (2010) 2267-2271. doi:10.1016/j.fuel.2010.01.028.

W] Roschat, T. Siritanon, T. Kaewpuang, B. Yoosuk, Economical and green biodiesel production process using river snail shells-derived heterogeneous catalyst and co-solvent method, Bioresour. Technol. 209 (2016) 343-350. doi:10.1016/j.biortech.2016.03.038. palm oil and sulfonated carbon catalyst derived from coconut meal residue for biodiesel production, Bioresour. Technol. 248 (2018) 199-203. 
doi:10.1016/j.biortech.2017.06.106.

528

529

530

531 [6]

532

533

534

535

536

537

538

539

540

541

542

543

544

545

546

547

548

549

550

551

552

553

554

555

556

557

558

[5] G. Baskar, I.A.E. Selvakumari, R. Aiswarya, Biodiesel production from castor oil using heterogeneous Ni doped $\mathrm{ZnO}$ nanocatalyst, Bioresour. Technol. 250 (2018) 793-798. doi:10.1016/j.biortech.2017.12.010.

[6] L.T. Thanh, K. Okitsu, L. Van Boi, Y. Maeda, Catalytic Technologies for Biodiesel Fuel Production and Utilization of Glycerol: A Review, Catalysts. 2 (2012) 191-222. doi:10.3390/catal2010191.

[7] S.P. Singh, D. Singh, Biodiesel production through the use of different sources and characterization of oils and their esters as the substitute of diesel: A review, Renew. Sustain. Energy Rev. 14 (2010) 200-216. doi:10.1016/j.rser.2009.07.017.

[8] L. Tu, K. Okitsu, Y. Sadanaga, N. Takenaka, Y. Maeda, A new co-solvent method for the green production of biodiesel fuel - Optimization and practical application, Fuel. 103 (2013) 742-748. doi:10.1016/j.fuel.2012.09.029.

[9] J.M. Encinar, A. Pardal, N. Sánchez, An improvement to the transesterification process by the use of co-solvents to produce biodiesel, Fuel.166 (2016) 51-58.

[10] V. Singh, M. Yadav, Y.C. Sharma, Effect of co-solvent on biodiesel production using calcium aluminium oxide as a reusable catalyst and waste vegetable oil, Fuel. 203 (2017) 360-369. doi:10.1016/j.fuel.2017.04.111.

[11] I. Ambat, V. Srivastava, M. Sillanpää, Recent advancement in biodiesel production methodologies using various feedstock: A review, Renewable and Sustainable Energy Reviews . 90 (2018) 356-369.

[12] S. Sakthivel, S. Halder, P.D. Gupta, Influence of Co-Solvent on the Production of Biodiesel in Batch and Continuous Process, International Journal of Green Energy. 10 (2013) 876-884. doi:10.1080/15435075.2012.727365.

[13] M. Feyzi, N. Hosseini, N. Yaghobi, R. Ezzati, Preparation, characterization, kinetic and thermodynamic studies of $\mathrm{MgO}-\mathrm{La}_{2} \mathrm{O}_{3}$ nanocatalysts for biodiesel production from sunflower oil, Chem. Phys. Lett. $677 \quad$ (2017) 19-29. doi:10.1016/j.cplett.2017.03.014.

[14] M. Saniger, Al-0 infrared vibrational frequencies of y-alumina, Materials Letters. 22 (1995) 109-113.

[15] L. Song, Y. Li, P. He, S. Zhang, X. Wu, S. Fang, J. Shan, D. Sun, Ultrasonics Sonochemistry Synthesis and sonocatalytic property of rod-shape $\mathrm{Sr}(\mathrm{OH})_{2} .8 \mathrm{H}_{2} \mathrm{O}$, 
[16] E. Rashtizadeh, F. Farzaneh, Z. Talebpour, Synthesis and characterization of $\mathrm{Sr}_{3} \mathrm{Al}_{2} \mathrm{O}_{6}$ nanocomposite as catalyst for biodiesel production, Bioresour. Technol. 154 (2014) 32-37. doi:10.1016/j.biortech.2013.12.014.

563

[17] W. Chen, Q. Liu, One-step in situ synthesis of strontium ferrites and strontium ferrites / graphene composites as microwave absorbing materials, RSC Advances. (2017) 40650-40657. doi:10.1039/c7ra05700h.

[18] H. Kang, M.S.P. Reddy, D. Kim, Effect of oxygen species on the positive flat-band voltage shift in $\mathrm{Al}_{2} \mathrm{O}_{3} / \mathrm{GaN}$ metal - insulator - semiconductor capacitors with
post-deposition annealing, J. Phys. D: Appl. Phys. 46 (2013). doi:10.1088/0022$3727 / 46 / 15 / 155101$.

[19] C. Maldonado, C.J. Lucio-ortiz, Low Concentration Fe-Doped Alumina Catalysts Using Sol-Gel and Impregnation Methods: The Synthesis, Characterization and Catalytic Performance during the Combustion of Trichloroethylene, Materials. (2014) 2062-2086. doi:10.3390/ma7032062.

[20] M. Wang, J. Han, Y. Hu, R. Guo, Mesoporous C, N-codoped $\mathrm{TiO}_{2}$ hybrid shells withenhanced visible light photocatalytic performance, RSC Adv. 7 (2017) 1551315520. doi:10.1039/C7RA00985B.

[21] S.S. Pitale, I.M. Nagpure, V. Kumar, O.M. Ntwaeaborwa, J.J. Terblans, H.C. Swart, Investigations on the low voltage cathodoluminescence stability and surface chemical behaviour using Auger and X-ray photoelectron spectroscopy on, Mater. Res. Bull. 46 (2011) 987-994. doi:10.1016/j.materresbull.2011.03.022.

[22] M. Tariq, S. Ali, F. Ahmad, M. Ahmad, M. Zafar, N. Khalid, M.A. Khan, Identification, FT-IR, NMR $\left({ }^{1} \mathrm{H}\right.$ and $\left.{ }^{13} \mathrm{C}\right)$ and GC/MS studies of fatty acid methyl esters in biodiesel from rocket seed oil, Fuel Process. Technol. 92 (2011) 336-341. doi:10.1016/j.fuproc.2010.09.025.

[23] M. Tariq, S. Ali, N. Khalid, Activity of homogeneous and heterogeneous catalysts, spectroscopic and chromatographic characterization of biodiesel: A review, Renew. Sustain. Energy Rev. $16 \quad$ (2012) 6303-6316. doi:10.1016/j.rser.2012.07.005. Temperature on the Yield of Biodiesel From Neem Seed Oil, Am. J. Energy Sci. 3 
(2016) 16-20.

592

593

594

595

596

597

598

599

600

601

602

603

604

605

606

607

608

609

610

611

612

613

614

615

616

617

618

619

620

621

622

[25] T. Eevera, K. Rajendran, S. Saradha, Biodiesel production process optimization and characterization to assess the suitability of the product for varied environmental conditions, Renew. Energy. 34 (2009) 762-765. doi:10.1016/j.renene.2008.04.006.

[26] V. Singh, F. Bux, Y.C. Sharma, A low cost one pot synthesis of biodiesel from waste frying oil (WFO) using a novel material, $\beta$-potassium dizirconate ( $\beta$ $\mathrm{K}_{2} \mathrm{Zr}_{2} \mathrm{O}_{5}$ ), Appl. Energy. (2016). doi:10.1016/j.apenergy.2016.02.135.

[27] M. Takase, Y. Chen, H. Liu, T. Zhao, L. Yang, X. Wu, Biodiesel production from non-edible Silybum marianum oil using heterogeneous solid base catalyst under ultrasonication, Ultrason. Sonochem. $21 \quad$ (2014) 1752-1762. doi:10.1016/j.ultsonch.2014.04.003.

[28] G. Kafui, A. Sunnu, J. Parbey, Effect of biodiesel production parameters on viscosity and yield of methyl esters : Jatropha curcas, Elaeis guineensis and Cocos nucifera, Alexandria Eng. J. 54 (2015) 1285-1290. doi:10.1016/j.aej.2015.09.011.

[29] F.F. Banihani, Transesterification and Production of Biodiesel from Waste Cooking Oil : Effect of Operation Variables on Fuel Properties, American Journal of Chemical Engineering . 4 (2017) 154-160. doi:10.11648/j.ajche.20160406.13.

[30] A.B. Chhetri, K.C. Watts, M.R. Islam, Waste Cooking Oil as an Alternate Feedstock for Biodiesel Production, Energies. 1 (2008) 3-18. doi:10.3390/en1010003.

[31] G. Knothe, K.R. Steidley, Kinematic viscosity of biodiesel fuel components and related compounds. Influence of compound structure and comparison to petrodiesel fuel components, Fuel. 84 (2005) 1059-1065. doi:10.1016/j.fuel.2005.01.016.

[32] A. Demirbas, Biodiesel: A realistic fuel alternative for diesel engines, Biodiesel A Realis. Fuel Altern. Diesel Engines. (2008) 1-208. doi:10.1007/978-1-84628-9958.

[33] H.G. Aleme, P.J.S. Barbeira, Determination of flash point and cetane index in diesel using distillation curves and multivariate calibration, Fuel. 102 (2012) 129_ 134. doi:10.1016/j.fuel.2012.06.015.

[34] W. V. Prescott, A.I. Schwartz, Nanorods and Nanomaterials Research Progress, 
http://books.google.es/books/about/Nanorods_Nanotubes_and_Nanomaterials_R es.html?id=a2De3CXrM8wC\&pgis=1.

[35] Kaur N, Ali A. Lithium ions-supported magnesium oxide as nano-sized solid catalyst for biodiesel preparation from mutton fat, Energy Sources, Part A Recover Util Environ Eff. 35 (2013)184-192.

[36] Tahvildari K, Anaraki YN, Fazaeli R, Mirpanji S, Delrish E. The study of CaO and

[37] Ambat I, Srivastava V, Haapaniemi E et al. Nano-magnetic potassium impregnated ceria as catalyst for the biodiesel production , Renew Energy 139 (2019)14281436.

[38] Galván G, Romero R, Ramírez A, Luz S, Baeza-jiménez R, Natividad R. Biodiesel production from used cooking oil and sea sand as heterogeneous catalyst, Fuel. 138(2014) 143-148. doi:10.1016/j.fuel.2014.07.053.

[39] Berrios M, Gutiérrez MC, Martín MA, Martín A. Application of the factorial design of experiments to biodiesel production from lard, Fuel Process Technol 90 (2009) 1447-1451. doi:10.1016/j.fuproc.2009.06.026.

[40] Ezekannagha CB, Ude CN, Onukwuli OD. Optimization of the methanolysis of lard oil in the production of biodiesel with response surface methodology, Egypt J Pet 26 (2017) 1001-1011. doi:10.1016/j.ejpe.2016.12.004.

[41] Alonso JA, Rasines I, Soubeyroux JL. Tristrontium dialuminum hexaoxide: An intricate superstructure of nanocatalyst, ChemInform. 29(1990) 4768-4771. doi:10.1021/ic00348a035.

[42] Fulmer GR, Miller AJM, Sherden NH, Gottlieb HE, Nudelman A, Stoltz BM, et al. NMR Chemical Shifts of Trace Impurities : Common Laboratory Solvents , Organics, and Gases in Deuterated Solvents Relevant to the Organometallic Chemist, Organometallics. 29 (2010) 2176-2179. doi:10.1021/om100106e.

[43] Alexandri E, Ahmed R, Siddiqui H, Choudhary MI, Tsiafoulis CG, Gerothanassis IP. High Resolution NMR Spectroscopy as a Structural and Analytical Tool for Unsaturated Lipids in Solution, Molecules 22 (2017) 1-71. 
doi:10.3390/molecules22101663.

656 [44] Piterina A V, Barlett J, Pembroke JT. C-NMR Assessment of the Pattern of Organic

657

658

659

660

661

662

663

664

665

666

667

668

669

670

671

672

673

674

675

676

677

678

679

680

681

682

683

684
Matter Transformation during Domestic Wastewater Treatment by Autothermal Aerobic Digestion ( ATAD ), International Journal of Environmental Research and Public Health 2009 2288-2306. doi:10.3390/ijerph6082288

[45] Megha U, Shijina K, Varghese G. Nanosized $\mathrm{LaCo}_{0.6} \mathrm{Fe}_{0.4} \mathrm{O}_{3}$ perovskites synthesized by citrate sol gel auto combustion method, Processing and Application of Ceramics 8 (2014) 87-92. doi:10.2298/PAC1402087M.

[46] Xu Y, He Y, Yuan X. Preparation of nanocrystalline $\mathrm{Sr}_{3} \mathrm{Al}_{2} \mathrm{O}_{6}$ powders via citric acid precursor 2007;172:99-102. doi:10.1016/j.powtec.2006.10.045.

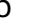

7

669

70

1

2

674

75

76 
691 Effect of different co-solvents on biodiesel production from various low-cost

\section{2 feedstocks using $\mathrm{Sr}$-Al double oxides}

693

694 Indu Ambat $^{\mathrm{a} *}$, Varsha Srivastava ${ }^{\mathrm{a}}$, Sidra Iftekhar ${ }^{\mathrm{a}}$, Esa Haapaniemi ${ }^{\mathrm{b}}$, Mika Sillanpää $^{\mathrm{a}}$

$695{ }^{a}$ Department of Green Chemistry, School of Engineering Science, Lappeenranta

696 University of Technology, Sammonkatu 12, FI-50130 Mikkeli, Finland

697 b Department of Organic Chemistry, University of Jyväskylä, Finland

$698 *$ Corresponding Author (E-mail: indu.ambat@lut.fi )

699

700 Supplementary materials

701 
(a)

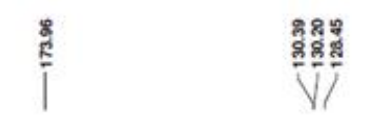

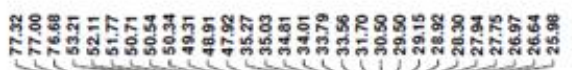

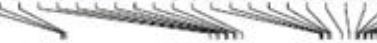

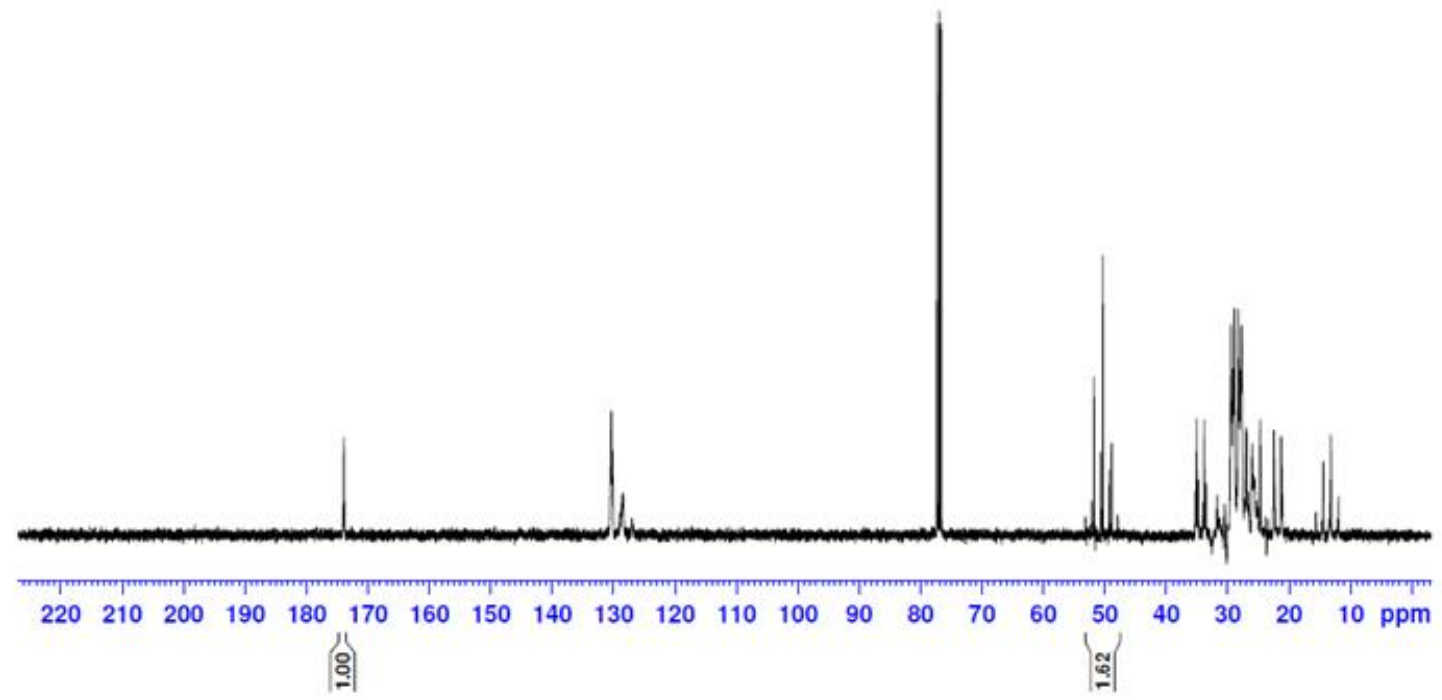

702

703

704

705 Fig S1 (a). The ${ }^{13} \mathrm{C}$ NMR for the biodiesel sample obtained from lardoil with Sr:

$\begin{array}{lll}706 & 0.33 \mathrm{Al}\end{array}$ 


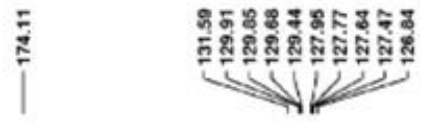

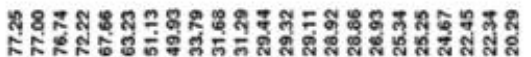

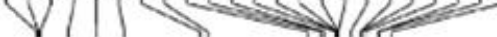

707

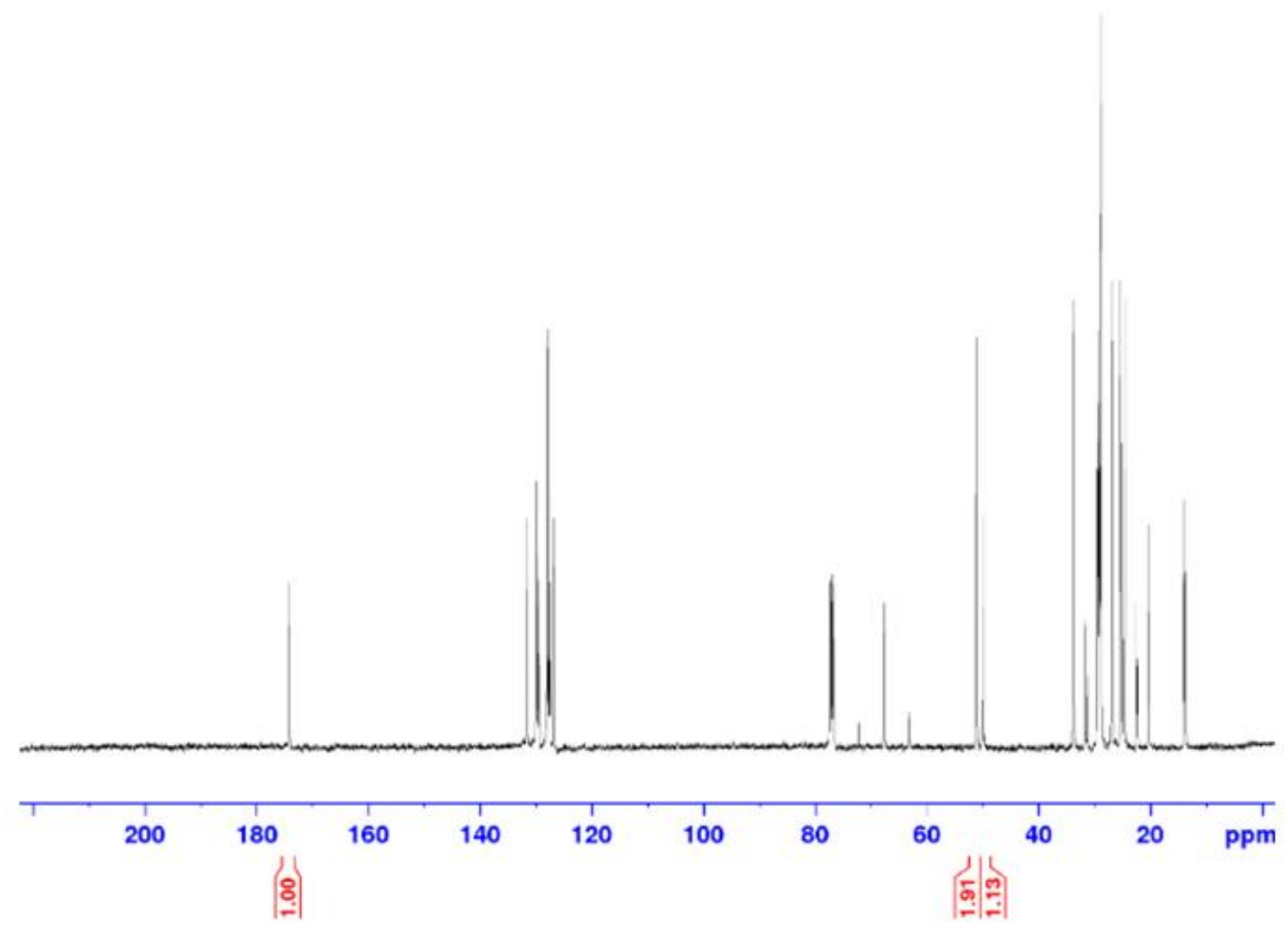

708

709

710

711

712 Fig S1 (b). The ${ }^{13} \mathrm{C}$ NMR for the biodiesel sample obtained from waste cooking oil 713 with Sr: 0.33Al.

714

715

716 